\title{
Results from Laboratory and Field Testing of Nitrate Measuring Spectrophotometers
}

Open-File Report 2015-1065 



\section{Results from Laboratory and Field Testing of Nitrate Measuring Spectrophotometers}

By Teri T. Snazelle

Open-File Report 2015-1065

U.S. Department of the Interior

U.S. Geological Survey 


\title{
U.S. Department of the Interior SALLY JEWELL, Secretary
}

\section{U.S. Geological Survey \\ Suzette M. Kimball, Acting Director}

\author{
U.S. Geological Survey, Reston, Virginia: 2015
}

For more information on the USGS - the Federal source for science about the Earth, its natural and living resources, natural hazards, and the environment—visit http://www.usgs.gov or call 1-888-ASK-USGS.

For an overview of USGS information products, including maps, imagery, and publications, visit http://www.usgs.gov/pubprod/.

Any use of trade, firm, or product names is for descriptive purposes only and does not imply endorsement by the U.S. Government.

Although this information product, for the most part, is in the public domain, it also may contain copyrighted materials as noted in the text. Permission to reproduce copyrighted items must be secured from the copyright owner.

Suggested citation:

Snazelle, T.T., 2015, Results from laboratory and field testing of nitrate measuring spectrophotometers: U.S. Geological Survey Open-File Report 2015-1065, 35 p., I Ued Idx.doi.org/10.3133/ofr20151065.

ISSN 2331-1258 (online) 


\section{Contents}

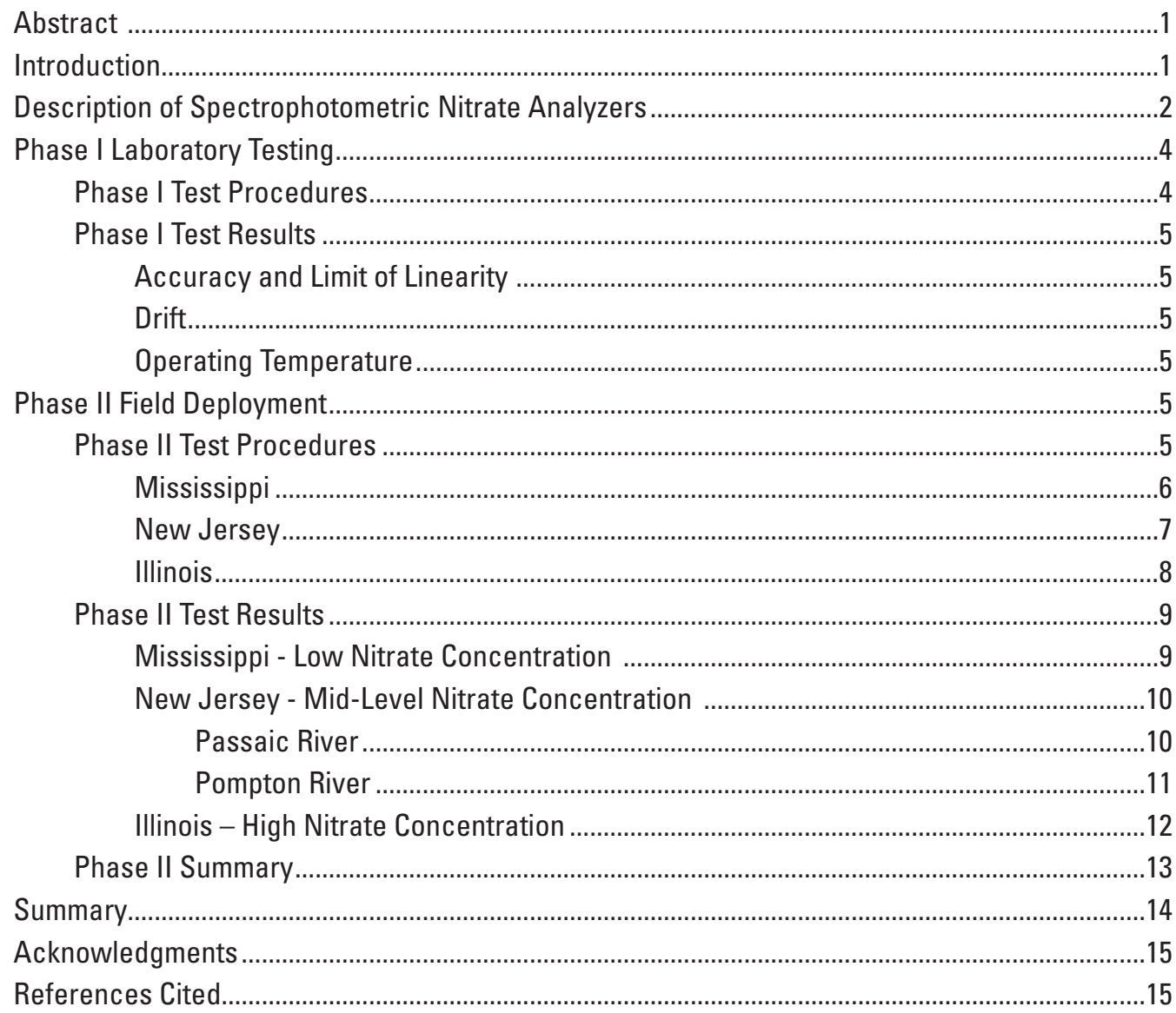

\section{Figures}

[Figures located at end of report]

1. Schematic Illustration of a spectrophotometer

2. Photos of nitrate analyzers: TriOS ProPS, Hach NITRATAX, S::CAN Spectro::lyser Satlantic SUNA, , and Satlantic SUNA V2

3. A schematic of a split or double-beam configuration

5. A schematic of a dual-beam configuration

4. A schematic of a single-beam configuration

6. Temperatures applied during temperature testing for nitrate analyzers

7. Accuracy results for TriOS, Hach, SUNA, and S::CAN ultraviolet nitrate analyzers

8. Drift results for TriOS, Hach, SUNA, and S::CAN ultraviolet nitrate analyzers

9. The difference between measured nitrate and standard concentration over an extended temperature range, for TriOS, and Hach, SUNA, and S::CAN

10. Top left, the S::CAN, Hach, TriOS, and SUNA analyzers next to an uninstalled deployment pipe. Top right, installed deployment pipes at the test pier. Bottom left, the S::CAN and Hach controllers, bottom right, the TriOS Tribox controller and the WaterLog 
H-500XL data logger interfaced with the SUNA

11. Two Bridges, New Jersey. View is looking downstream from the gage house

12. Two Bridges sampling system. Pictured on the left is the open basin that was sequentially filled with water from the three intakes

13. Agricultural fields surrounding Kickapoo Creek

14. Site of Kickapoo Creek restoration project including The Grove subdivision seen in the background

15. Installation of the nitrate analyzers at USGS site 05579610, Bloomington, Illinois

16. Stacked time series plots for measured nitrate concentration in milligram Nitrogen per liter plotted for the East Pearl River gage height in feet, stream velocity in feet per second, temperature in degrees Celsius, turbidity in formazin nephelometric units, and specific conductance in microseimens per centimeter

17. Stacked time series plots for measured nitrate concentration in milligram nitrogen per liter plotted for the Passaic River gage height in feet, temperature in degrees Celsius, turbidity in formazin nephelometric units, and dissolved organic carbon in milligrams per liter

18. Stacked time series plots for measured nitrate concentration in milligrams nitrogen per liter plotted for the Pompton River gage height in feet, temperature in degrees Celsius, turbidity in formazin nephelometric units, and dissolved organic carbon in milligrams per liter

19. Stacked time series plots for measured nitrate concentration in milligrams nitrogen per liter plotted for Kickapoo Creek gage height in feet, and discharge in cubic feet per second

20. Difference in milligrams nitrogen per liter between the measured and reference nitrate concentrations from eight analyzers at three USGS sites compared to the reference nitrate concentration

21. Statistical distribution of the differences in measured and discrete sample nitrate concentration from three measurement sites

\section{Tables}

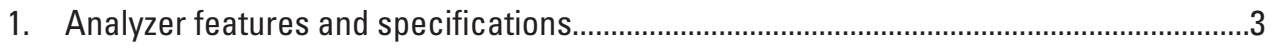

2. Nitrate plus nitrite results from the East Pearl River ......................................................10

3. Nitrate plus nitrite results from the Passaic River ........................................................11

4. Nitrate plus nitrite results from the Pompton River .......................................................12

5. Nitrate plus nitrite results from Kickapoo Creek ...........................................................13

6. Statistical distribution of the analyzer model's accuracy in milligrams nitrogen per liter 


\section{Conversion Factors}

\begin{tabular}{|c|c|c|}
\hline Multiply & By & To obtain \\
\hline \multicolumn{3}{|c|}{ Length } \\
\hline inch (in.) & 2.54 & centimeter $(\mathrm{cm})$ \\
\hline foot $(\mathrm{ft})$ & 0.3048 & meter (m) \\
\hline mile (mi) & 1.609 & kilometer $(\mathrm{km})$ \\
\hline \multicolumn{3}{|c|}{ Area } \\
\hline acre & 4047 & square meter $\left(\mathrm{m}^{2}\right)$ \\
\hline \multicolumn{3}{|c|}{ Flow rate } \\
\hline foot per second (ft/s) & 0.3048 & meter per second $(\mathrm{m} / \mathrm{s})$ \\
\hline cubic foot per second $\left(\mathrm{ft}^{3} / \mathrm{s}\right)$ & 0.02832 & cubic meter per second $\left(\mathrm{m}^{3} / \mathrm{s}\right)$ \\
\hline
\end{tabular}

International System of Units to Inch/Pound

\begin{tabular}{|c|c|c|}
\hline Multiply & By & To obtain \\
\hline \multicolumn{3}{|c|}{ Length } \\
\hline centimeter $(\mathrm{cm})$ & 0.3937 & inch (in.) \\
\hline millimeter (mm) & 0.03937 & inch (in.) \\
\hline micrometer $(\mu \mathrm{m})$ & 0.00003937 & inch (in.) \\
\hline nanometer (nm) & 0.00000003937 & inch (in.) \\
\hline meter (m) & 3.281 & foot $(\mathrm{ft})$ \\
\hline millimeter (mm) & 0.003281 & foot $(\mathrm{ft})$ \\
\hline \multicolumn{3}{|c|}{ Volume } \\
\hline liter (L) & 33.82 & ounce, fluid (fl. oz) \\
\hline milliliter (mL) & 0.0338 & ounce, fluid (fl. oz) \\
\hline \multicolumn{3}{|c|}{ Mass } \\
\hline kilogram (kg) & 2.205 & pound avoirdupois (lb) \\
\hline milligram (mg) & 0.0000022 & pound avoirdupois (lb) \\
\hline
\end{tabular}

Temperature in degrees Celsius $\left({ }^{\circ} \mathrm{C}\right)$ may be converted to degrees Fahrenheit $\left({ }^{\circ} \mathrm{F}\right)$ as ${ }^{\circ} \mathrm{F}=\left(1.8 \times{ }^{\circ} \mathrm{C}\right)+32$.

Temperature in degrees Fahrenheit $\left({ }^{\circ} \mathrm{F}\right)$ may be converted to degrees Celsius $\left({ }^{\circ} \mathrm{C}\right)$ as ${ }^{\circ} \mathrm{C}=\left({ }^{\circ} \mathrm{F}-32\right) / 1.8$. 



\title{
Results from Laboratory and Field Testing of Nitrate Measuring Spectrophotometers
}

\author{
By Teri T. Snazelle
}

\begin{abstract}
Five ultraviolet (UV) spectrophotometer nitrate analyzers were evaluated by the U.S. Geological Survey (USGS) Hydrologic Instrumentation Facility (HIF) during a two-phase evaluation. In Phase I, the TriOS ProPs (10-millimeter (mm) path length), Hach NITRATAX plus sc (5-mm path length), Satlantic Submersible UV Nitrate Analyzer (SUNA, 10-mm path length), and S::CAN Spectro::lyser (5-mm path length) were evaluated in the HIF Water-Quality Servicing Laboratory to determine the validity of the manufacturer's technical specifications for accuracy, limit of linearity (LOL), drift, and range of operating temperature. Accuracy specifications were met in the TriOS, Hach, and SUNA. The stock calibration of the S::CAN required two offset adjustments before the analyzer met the manufacturer's accuracy specification. Instrument drift was observed only in the $\mathrm{S}:$ :CAN and was the result of leaching from the optical path insert seals. All tested models, except for the Hach, met their specified LOL in the laboratory testing. The Hach's range was found to be approximately 18 milligrams nitrogen per liter (mg-N/L) and not the manufacturer-specified $25 \mathrm{mg}-\mathrm{N} / \mathrm{L}$. Measurements by all of the tested analyzers showed signs of hysteresis in the operating temperature tests. Only the SUNA measurements demonstrated excessive noise and instability in temperatures above 20 degrees Celsius $\left({ }^{\circ} \mathrm{C}\right)$. The SUNA analyzer was returned to the manufacturer at the completion of the Phase II field deployment evaluation for repair and recalibration, and the performance of the sensor improved significantly.

In Phase II, the analyzers were deployed in field conditions at three different USGS sites. The measured nitrate concentrations were compared to discrete (reference) samples analyzed by the Direct UV method on a Shimadzu UV1800 bench top spectrophotometer, and by the National Environmental Methods Index (NEMI) method I-2548-11 at the USGS National Water Quality Laboratory. The first deployment at USGS site 0249620 on the East Pearl River in Hancock County, Mississippi, tested the ability of the TriOs ProPs (10-mm path length), Hach NITRATAX (5 mm), Satlantic SUNA (10 mm), and the S::CAN Spectro::lyser $(5 \mathrm{~mm})$ to accurately measure low-level (less than $2 \mathrm{mg}-\mathrm{N} / \mathrm{L}$ ) nitrate concentrations while observing the effect turbidity and colored dissolved organic matter (CDOM) would have on the analyzers' measurements. The second deployment at USGS site 01389005 Passaic River below Pompton River at Two Bridges, New Jersey, tested the analyzer's accuracy in mid-level (2-8 mg-N/L) nitrate concentrations. This site provided the means to test the analyzers' performance in two distinct matrices - the Passaic and the Pompton Rivers. In this deployment, three instruments tested in Phase I (TriOS, Hach, and SUNA) were deployed with the S::CAN Spectro::lyser $(35 \mathrm{~mm})$ already placed by the New Jersey Water Science Center (WSC). The third deployment at USGS site 05579610 Kickapoo Creek at 2100E Road near Bloomington, Illinois, tested the ability of the analyzers to measure high nitrate concentrations (greater than $8 \mathrm{mg}-\mathrm{N} / \mathrm{L}$ ) in turbid waters. For Kickapoo Creek, the HIF provided the TriOS $(10 \mathrm{~mm})$ and S::CAN $(5 \mathrm{~mm})$ from Phase I, and a SUNA V2 $(5 \mathrm{~mm})$ to be deployed adjacent to the Illinois WSC-owned Hach $(2 \mathrm{~mm})$. A total of 40 discrete samples were collected from the three deployment sites and analyzed. The nitrate concentration of the samples ranged from $0.3-22.2 \mathrm{mg}-\mathrm{N} / \mathrm{L}$. The average absolute difference between the TriOS measurements and discrete samples was $0.46 \mathrm{mg}-\mathrm{N} / \mathrm{L}$. For the combined data from the Hach 5-mm and 2-mm analyzers, the average absolute difference between the Hach samples and the discrete samples was $0.13 \mathrm{mg}-\mathrm{N} / \mathrm{L}$. For the SUNA and SUNA V2 combined data, the average absolute difference between the SUNA samples and the discrete samples was $0.66 \mathrm{mg}-\mathrm{N} / \mathrm{L}$. The average absolute difference between the S::CAN samples and the discrete samples was $0.63 \mathrm{mg}-\mathrm{N} / \mathrm{L}$.
\end{abstract}

\section{Introduction}

The U.S. Geological Survey (USGS) Hydrologic Instrumentation Facility (HIF) evaluates the performance of instruments and equipment that are used to directly measure hydrologic and biogeochemical data. Instrument and equipment evaluations are done primarily to determine if particular devices would be suitable for use by USGS personnel for hydrologic data collection. 
Results from Laboratory and Field Testing of Nitrate Measuring Spectrophotometers

This report documents the laboratory and field evaluation of commercially available self-contained ultraviolet (UV) spectrophotometer nitrate analyzers. Evaluation reports document the results at the time of testing, and may or may not reflect future conditions resulting from improvements to the instrumentation and/or software updates. Five nitrate analyzer models were evaluated during a two-phase evaluation. In Phase I, four analyzer models were tested in laboratory conditions at the HIF for compliance to the manufacturer's specifications and for accuracy in National Institute of Standards and Technology (NIST) traceable nitrate standards. The SUNA V2 was not available when Phase I testing was conducted. In Phase II, the analyzers were field tested at three USGS sites and their measured nitrate concentrations were compared to discrete samples collected at the sites. Additional information on the nitrate analyzers and their proper use in environmental waters can be found in the USGS Techniques and Methods 1-D5 "Optical Techniques for the Determination of Nitrate in Environmental Waters: Guidelines for Instrument Selection, Operation, Deployment, Maintenance, Quality Assurance, and Data Reporting (Pellerin and others, 2013). After a brief description of the analyzer models, the laboratory and field procedures and test results are described.

\section{Description of Spectrophotometric Nitrate Analyzers}

Recent advances in technology have led to the development of self-contained, submersible analyzers, which can deliver continuous monitoring for nitrate plus nitrite concentration. In contrast to some previous models that relied on reagents and cadmium reduction and visible spectrophotometry, these analyzers provide a chemical-free and cost-effective solution through the use of UV spectrophotometry (American Public Health Association, 1989). The optical system of a spectrophotometer or spectrometer is composed of three main parts (fig. 1):

- a light source (lamp) —usually deuterium or xenon,

- a sample optical path length - usually 5-100 millimeters (mm), and

- the spectrometer detector.

The matrix to be tested (normally water) flows into the instrument's optical path length, and is illuminated with a beam of light. This same light beam is separated into various wavelengths of the ultraviolet/visible (UV/Vis) spectrum (190-740 micrometers) by means of either a diffraction grating or monochromatic optical filter, and projected on a photoelectric detector. The energy measured by the spectrophotometer for each wavelength produces a raw "spectral fingerprint" or absorption spectrum of the water sample. The raw absorption spectrum is processed by proprietary signal processing algorithms into a filtered absorption spectrum. The nitrate concentration is calculated from the filtered absorption spectrum using the Beer-Lambert Law, or Beer's Law.

Eight different UV nitrate analyzers with varying path lengths were evaluated: the TriOS ProPS (10 mm) (TriOS Mess- und Datentechnick GmbH [2012]), Hach NITRATAX plus sc (2 mm) (Danaher Business System [2012a]), the Hach NITRATAX plus sc (5 mm), the Satlantic SUNA (10 mm), the Satlantic SUNA V2 $(5 \mathrm{~mm})$ (Danaher Business System [2012b]), and three S::CAN Spectro::lysers (5 and $35 \mathrm{~mm}$ ) (S::can messtechnik GmbH [2012]) (fig. 2). The path length of the analyzer plays a central role in determining how well the instrument compensates for interferences such as turbidity. In general, a shorter path length will limit the sensitivity of the analyzer for low concentrations, but will generally increase the nitrate detection range and minimize adverse effects from high turbidity and suspended sediment. A longer path length will provide greater sensitivity for low-level concentrations, but will reduce the detection range and increase the effect of interferences. The analyzers are available commercially with prices varying from $\$ 15,000$ to $\$ 23,000$, depending on the accessories. Analyzers differ in their light sources, optical configuration, communication protocols, antifouling measures, and algorithms used to compute nitrate from the UV absorbance of the water sample. Table 1 gives a summary of each unit's available features and technical specifications and the path lengths of the tested analyzers. Information on the TriOS range of operation, accuracy, and detection limit were unavailable at the time of this evaluation; this information was included in Pellerin and others (2013). Limit of linearity (LOL) can be defined as the point at which the instrument's performance is no longer linear, and the accuracy of the measurement no longer meets the specification (Finite Element Method (FEM), 2010). The operating range of the analyzer should be bracketed at the lower end by the limit of detection, which is the smallest concentration that can be reliably measured, and at the upper end by the limit of linearity.

The most common optical configurations in a spectrometer are single beam, double or "split" beam, and dual beam. The TriOS and S::CAN have a split or double-beam configuration. A split-beam configuration divides a single light beam into the primary or measurement beam and a reference beam prior to the light beam passing through the water sample (HunterLab Inc., 2008). The reference beam is used to monitor the age of the lamp and to make adjustments for changes in the lamp output, electronic noise, and stray light (fig. 3). 
Table 1. Analyzer features and specifications.

[UV, ultraviolet; $\mathrm{nm}$, nanometer; mm, millimeter; $\mathrm{mg} / \mathrm{L}$, milligrams per liter; \%, percent; ${ }^{\circ} \mathrm{C}$, degree Celsius; dia, diameter; kg, kilogram; max, maximum; $\mathrm{m}$, meter; $\mathrm{V}$, volt; mA, milliamp; w.i.g, whichever is greater]

\begin{tabular}{|c|c|c|c|c|c|}
\hline Unit & TriOS ProPS & $\begin{array}{l}\text { HACH NITRATAX } \\
\text { plus sc }\end{array}$ & Satlantic SUNA & Satlantic SUNA V2 & S::CAN Spectro::Iyser \\
\hline Detector type & $\begin{array}{l}\text { UV (200-385 nm) } \\
\text { spectral analysis }\end{array}$ & $\begin{array}{l}\text { UV (210 } \mathrm{nm} \text { and } \\
350 \mathrm{~nm}) \text { spectral } \\
\text { analysis }\end{array}$ & $\begin{array}{l}\text { UV (190-370 nm) } \\
\text { spectral analysis }\end{array}$ & $\begin{array}{l}\text { UV (190-370 nm) } \\
\text { spectral analysis }\end{array}$ & $\begin{array}{l}\text { UV-Vis }(220-720 \mathrm{~nm}) \\
\text { spectral analysis }\end{array}$ \\
\hline $\begin{array}{l}\text { Sample path } \\
\text { length }(\mathrm{mm})\end{array}$ & $1-60$ (semifixed) & 1,2, and 5 (fixed) & 10, (fixed) & 5,10, (fixed) & $0.5-100$ (semifixed) \\
\hline $\begin{array}{l}\text { Sample path } \\
\text { length }(\mathrm{mm}) \\
\text { tested }\end{array}$ & 10 & 2 and 5 & 10 & 5 & 5 and 35 \\
\hline Lamp & Deuterium & Xenon & Deuterium & Deuterium & Xenon \\
\hline Detector & Zeiss & Patented 2-beam & Zeiss 256 diodes & Zeiss & Zeiss 256 diodes \\
\hline $\begin{array}{l}\text { Optical } \\
\text { configuration }\end{array}$ & Split beam & Dual beam & Single beam & Single beam & Split beam \\
\hline $\begin{array}{l}\mathrm{NO}_{3}-\mathrm{N} \\
\text { range }(\mathrm{mg} / \mathrm{L})\end{array}$ & Not available & $0.1-25$ & $0.007-28$ & $0.031-56$ & $0.00-70$ (typical) \\
\hline Accuracy & Not available & $\begin{array}{l}+/-3 \% \text { of mean } \\
+/-0.5 \mathrm{mg} / \mathrm{L}\end{array}$ & $\begin{array}{l}0.028(\mathrm{mg} / \mathrm{l}) \text { or } \\
\pm 10 \%\end{array}$ & $\begin{array}{l}0.028(\mathrm{mg} / \mathrm{l}) \text { or } \\
\pm 10 \%\end{array}$ & $\begin{array}{l}2 \%+1 /(\text { optical path } \\
\text { length) } \mathrm{mg} / \mathrm{L}\end{array}$ \\
\hline $\begin{array}{l}\text { Detection limit } \\
(\mathrm{mg} / \mathrm{L})\end{array}$ & Not available & 0.10 & 0.007 & 0.031 & 0.005 \\
\hline $\begin{array}{l}\text { Operating } \\
\text { temperature } \\
\text { range }\end{array}$ & $0-50^{\circ} \mathrm{C}$ & $0-40^{\circ} \mathrm{C}$ & $0-40^{\circ} \mathrm{C}$ & $0-35^{\circ} \mathrm{C}$ & $0-45^{\circ} \mathrm{C}$ \\
\hline Dimensions & $\begin{array}{l}68 \mathrm{~mm} \text { dia } \times 520 \\
\mathrm{~mm}\end{array}$ & $\begin{array}{l}75 \mathrm{~mm} \text { dia } \times 323 \\
\mathrm{~mm}\end{array}$ & $\begin{array}{l}50 \mathrm{~mm} \text { dia } \times 530 \\
\mathrm{~mm}\end{array}$ & $\begin{array}{l}119 \text { mm x } 624 \\
\text { mm (with wiper) }\end{array}$ & $44 \mathrm{~mm}$ dia x $647 \mathrm{~mm}$ \\
\hline Weight (in air) & $4.9 \mathrm{~kg}$ & $3.6 \mathrm{~kg}$ & $2.5 \mathrm{~kg}$ & $3.1 \mathrm{~kg}$ & $2.1 \mathrm{~kg}$ \\
\hline Depth max & $1500 \mathrm{~m}$ & $100 \mathrm{~m}$ & $500 \mathrm{~m}$ & $\begin{array}{l}500 \mathrm{~m} \\
100 \mathrm{~m} \text { (with } \\
\text { wiper) }\end{array}$ & Not available \\
\hline Battery & $24 \mathrm{~V}$ & $12 \mathrm{~V}$ or $24 \mathrm{~V}$ & $12 \mathrm{~V}$ & $12 \mathrm{~V}$ & $12 \mathrm{~V}$ \\
\hline $\begin{array}{l}\text { Current draw } \\
\text { (average) }\end{array}$ & Not available & Not available & $0.625 \mathrm{amp}$ & $0.625 \mathrm{amp}$ & $20 \mathrm{~W} \max$ \\
\hline Communications & $\mathrm{RS} 232$ & $\begin{array}{l}\text { Modbus/RS485, } \\
\text { Modbus/RS232, } \\
\text { 4-20 mA }\end{array}$ & $\begin{array}{l}\text { RS232, SDI-12, } \\
\text { 4-20 mA }\end{array}$ & $\begin{array}{l}\text { RS232, SDI-12, } \\
\text { 4-20 mA }\end{array}$ & $\begin{array}{l}\text { Modbus/RS232, } \\
\text { Modbus/RS485, } \\
\text { 4-20 mA, SDI-12 }\end{array}$ \\
\hline
\end{tabular}

The SUNA and SUNA V2 have a single-beam configuration. For this optical configuration, there is one beam from the light source. The beam passes through the monochromator, which sequentially separates and focuses the wavelengths of light onto the detector. The source is not "split" to provide a reference beam. For most single-beam instruments to perform well, the light source, detector, and electronics must be reasonably stable (fig. 4). The Hach (2 and $5 \mathrm{~mm}$ ) is designed with a dual-beam fixed wavelength configuration (fig. 5). A dual-beam spectrometer has a mirror that splits a single beam of light into primary and secondary beams after passing through the water sample, and directs the beams onto two separate detectors (Comerford, 2011; Hach NITRATAX http://www.hach.com., September 2012). The Hach uses a primary beam wavelength of 210 nanometers (nm) to measure nitrate plus nitrite, and a secondary reference beam wavelength of $350 \mathrm{~nm}$ to correct for interferences such as turbidity or organic matter. This type of configuration accounts for fluctuations in the lamp and electronics as well as interferences associated with the water sample matrix. Baseline noise associated with a double or dual beam is normally much lower than the other configurations (Comerford, 2011). 


\section{Phase I Laboratory Testing}

\section{Phase I Test Procedures}

From August 2011 through January 2012, the analyzers were evaluated in a controlled laboratory setting for accuracy, limit of linearity (LOL), drift, and operating range of temperature. Measured nitrates were compared to standard dilutions with known nitrate concentrations that were prepared from two independent nitrate standards (McNaught and Wilkinson, 1997). Manufacturing technical specifications were compared to the laboratory results to determine their validity. An $11.3 \pm 1$ percent mg-N/L Hach-Lange standard (LCW825), and a 1,000 \pm 0.5 percent mg-N/L Ricca Chemical standard (5459-16) were used to prepare all working standard dilutions $(3.7,5.0,5.7,10.0,11.3,16.7,20.0,25.0,40.0$, and $50.0 \mathrm{mg}-\mathrm{N} / \mathrm{L})$. Standard dilutions were prepared using the formula:

$$
X=\frac{(C n * V n)}{(C s)}
$$

where

$$
\begin{aligned}
& \mathrm{X}=\quad \text { volume of nitrate stock standard to be diluted in milliliters }(\mathrm{mL}) \\
& \mathrm{Cn}=\quad \text { concentration of the new standard in } \mathrm{mg} / \mathrm{L} \\
& \mathrm{Vn}=\text { total volume of the new standard in } \mathrm{mL} \text {; and } \\
& \mathrm{Cs}=\quad \text { concentration of the standard to be diluted in } \mathrm{mg} / \mathrm{L} \text {. }
\end{aligned}
$$

The uncertainty of each standard dilution was estimated at 3 percent at 95-percent confidence and was calculated from the sum of the squares of the following variables.

- 1 percent error from the larger impurity of the two certified stock standards ( 1 and 0.5 percent)

- A single dilution of the stock standard using Class A volumetric glassware with an associated error of \pm 0.5 percent

- 1 percent error from the standard deviation from five replicates of a $5.0 \mathrm{mg}-\mathrm{N} / \mathrm{L}$ solution

Normal distribution was assumed. Standard accuracy was verified with a calibrated bench top Shimadzu UV1800 spectrophotometer, and standards with deviations greater than \pm 3 percent from the target concentration were discarded and reprepared.

The analyzers were evaluated at room temperature for accuracy, LOL, and drift using the "as received" or manufacturer's stock calibrations. The "stock calibration" is the factory or manufacturer's calibration that has not been altered. The analyzers are shipped calibrated; however, most manufacturers encourage the user to adjust the calibration for local matrix effects. During accuracy and LOL tests, approximately 100 standard measurements were made by each analyzer. Ten replicated measurements were collected at each concentration. Nitrate difference was calculated as measured minus standard; therefore negative values indicated a low bias, and positive values indicated a high bias by the unit. For the drift test, the analyzers were filled with the $11.3 \mathrm{mg}-\mathrm{N} / \mathrm{L} \pm 1$ percent standard, sealed with parafilm to prevent external contamination, and programmed to measure nitrate every 15 minutes for approximately 20 hours. The drift tests were conducted at room temperature.

Operating temperature specifications were examined at the HIF using an ESPEC environmental chamber over a temperature range of 5-40 degrees Celsius $\left({ }^{\circ} \mathrm{C}\right)$. Except for the S::CAN, the analyzers were tested using the manufacturers' stock calibrations. A high bias was observed in the S::CAN's measurements during the initial room temperature testing. To correct for this bias, an offset was programmed into the unit by the manufacturer prior to the temperature specification testing. Each analyzer was subjected to the same environmental chamber, temperature cycling program, and $10 \mathrm{mg}-\mathrm{N} / \mathrm{L}$ standard. Chamber temperatures were set at $20,5,20,40$, and $20^{\circ} \mathrm{C}$ (fig. 6). The analyzers and the nitrate standard were allowed to acclimate overnight at $20^{\circ} \mathrm{C}$ in the chamber prior to the start of the temperature test. The chamber temperature was slowly ramped to the next test temperature and held for 2 hours to stabilize the sample temperature of the analyzers prior to initiating measurements. 


\section{Phase I Test Results}

\section{Accuracy and Limit of Linearity}

The TriOS specifications list a spectral accuracy of $0.2 \mathrm{~nm}$ and no measurement accuracy in concentration. The detection range is listed as $0-100 \mathrm{mg} / \mathrm{L}$ "depending on water matrix and components." Because of the ambiguous specifications, the data were used to describe the accuracy limits achieved by the TriOS in testing. As shown in figure 7, TriOS met a \pm 10 percent accuracy specification with few exceptions between zero and $16.7 \mathrm{mg} / \mathrm{L}$, but accuracy limits achieved above $20 \mathrm{mg} / \mathrm{L}$ were up to 25 percent, with sensor readings biased high at high concentrations. Manufacturing specifications for the Hach 5-mm path length claim a detection range of $0.1-25 \mathrm{mg}-\mathrm{N} / \mathrm{L}$. Test results indicated that the analyzer was linear to $18 \mathrm{mg}-\mathrm{N} / \mathrm{L}$, but failed to meet the manufacturing specification at higher concentrations. The SUNA's performance was based upon its freshwater calibration, and met the manufacturer's accuracy specifications with few exceptions. SUNA's test results indicated a much higher LOL than the specified detection range of $0.007-28 \mathrm{mg}-\mathrm{N} / \mathrm{L}$. The SCAN stock calibration resulted in a curvilinear response, with a 14-17-percent bias between 5.6 and $16.7 \mathrm{mg} / \mathrm{L}$. Like the SUNA, the S::CAN demonstrated a higher limit of linearity.

\section{Drift}

The results of the drift test at a nitrate concentration of $10 \mathrm{mg}-\mathrm{N} / \mathrm{L}$ for the analyzers are shown in figure 8 . The TriOS data set had a standard deviation (SD) of $0.17 \mathrm{mg}-\mathrm{N} / \mathrm{L}$, and showed a slight downward trend. There was no indication of trending or obvious drift in the Hach data. The Hach showed good stability during the drift test, and resulted in a $0.04 \mathrm{mg}-\mathrm{N} / \mathrm{L}$ SD. The SD for the SUNA's data set was $0.41 \mathrm{mg}-\mathrm{N} / \mathrm{L}$. There was little indication of drift, but there was evidence of noise or instability. The S::CAN drift test was repeated three times due to a large persistent upward trend in the data. Leaching of the 5-mm path length insert seals was proposed by the manufacturer as an explanation of the upward drift. To test this theory, the test was repeated over a longer period of time. During the retest, the increase in measured concentration plateaued after 3 days, as would be expected if the seals were leaching. The same test was performed on another S::CAN Spectro::lyser equipped with a 35-mm sample window without insert seals. Data from this S::CAN showed no indication of trending or of drift. The 5-mm window data set resulted in an SD of $1.1 \mathrm{mg}-\mathrm{N} / \mathrm{L}$. In contrast, the $35-\mathrm{mm}$ window data set showed a standard deviation of $0.04 \mathrm{mg}-\mathrm{N} / \mathrm{L}$, or roughly 29 times less than the 5-mm window. This finding supported the theory that the seals were leaching and changing the concentration in the previous test. The effect of seal leachate on instrument drift should be minimal in many applications with flowing water such as rivers.

\section{Operating Temperature}

The effect of temperature on measurement accuracy was also evaluated. TriOS and Hach met their respective accuracy limits (fig. 9), and demonstrated good stability during the temperature cycling. However, a hysteresis effect, where measured concentrations at the same temperature are higher for rising temperatures than for falling temperatures, was evident in the data. The average difference in TriOS nitrate measurements below $20^{\circ} \mathrm{C}$ was $0.3 \mathrm{mg} / \mathrm{L}$, and above $20^{\circ} \mathrm{C}$ was $0.4 \mathrm{mg} / \mathrm{L}$. For the Hach, the average difference in concentration below $20^{\circ} \mathrm{C}$ was $0.2 \mathrm{mg} / \mathrm{L}$, and above $20^{\circ} \mathrm{C}$ the difference increased to an average of $0.3 \mathrm{mg} / \mathrm{L}$. The SUNA met the accuracy criteria at temperatures less than $25^{\circ} \mathrm{C}$, and showed a negligible hysteresis effect in data below $20^{\circ} \mathrm{C}$. For temperatures above $25^{\circ} \mathrm{C}$, the measurements became noisier and failed to meet the manufacturer's accuracy specifications. A retest at temperatures above $25^{\circ} \mathrm{C}$ confirmed the results of the first test; however, testing was limited to a single unit. As stated earlier, an offset was applied to the S::CAN's stock calibration prior to the temperature test to correct for the high bias observed during the room temperature testing. After the application of the offset, a low bias became apparent in the S::CAN's data. The S::CAN measurements in the $10 \mathrm{mg}-\mathrm{N} / \mathrm{L}$ standard were an average of $1.9 \mathrm{mg}-\mathrm{N} / \mathrm{L}$ lower than the standard value, but there was no apparent drift over the temperature cycle. The S::CAN results also showed evidence of hysteresis similar to the TriOS. The average difference in concentration below $20^{\circ} \mathrm{C}$ was $0.3 \mathrm{mg}-\mathrm{N} / \mathrm{L}$, and $0.4 \mathrm{mg}-\mathrm{N} / \mathrm{L}$ above $20^{\circ} \mathrm{C}$.

\section{Phase II Field Deployment}

\section{Phase II Test Procedures}

Phase II was an extensive evaluation that used three deployment sites to evaluate the analyzers performance in field conditions. The sites were located in Mississippi, New Jersey, and Illinois. Nitrate concentrations were low at the Mississippi site $(<1 \mathrm{mg}-\mathrm{N} / \mathrm{L})$, mid-level at the New Jersey site $(0.6-4.1 \mathrm{mg}-\mathrm{N} / \mathrm{L})$, and high at the Illinois site $(16.6-22.2 \mathrm{mg}-\mathrm{N} / \mathrm{L})$. The 
Results from Laboratory and Field Testing of Nitrate Measuring Spectrophotometers

analyzers' measured values were collected raw, and were not corrected for fouling or calibration drift as per "USGS Techniques and Methods 1-D3" (Wagner, 2006), nor matrix bias as per "USGS Techniques and Methods 1-D5" (Pellerin and others, 2013).

\section{Mississippi}

The first deployment from February to May 2012 was at USGS site 02492620 located on the East Pearl River in Hancock County, Mississippi. The Pearl River begins in Neshoba County, Mississippi, and splits into the East Pearl and the West Pearl Rivers, 50 miles above the mouth of the Pearl River. The East Pearl empties into Lake Borgne where the Pearl River Channel meets the Gulf Intracoastal Waterway. USGS site 02492620 is tidally affected. Site conditions, including gage height, temperature, and water quality, are monitored routinely as part of the continuous monitoring program. The analyzers were deployed in separate 4-inch (in.) schedule 40 polyvinyl chloride (PVC) pipes. The TriOS controller, the Tribox, and the Water $\log C$ H-500XL data logger used to interface the SUNA were mounted in the adjacent gage house (fig. 10; bottom right). The S::CAN and the Hach controllers were mounted on the test pier. Each analyzer was secured so that the optical window would hang at a depth of 11 feet ( $\mathrm{ft}$ ) below the pipe cap and would remain submerged in the river over the anticipated range of stages. The analyzers sampled every half hour.

Three of the four analyzers were deployed with their stock calibrations. The S::CAN was initially deployed with the manufacturer's "global river calibration," but as the deployment progressed two adjustments to the analyzer's calibration offset were required on March 6 and April 3, 2012. Following the advice of the SUNA manufacturer, the measurement integration window was reduced from 750 to 250 milliseconds on March 20 to improve the unit's performance. The integration window setting of a spectrometer determines how much light the detector is exposed to, and is analogous to the shutter speed of a camera. The higher the integration time, the longer the detector is exposed to light. Too much light can cause a "blinding" effect and will negatively affect the measurements. The SUNA was not recalibrated, and data points collected before the reduction of the integration window were not used to assess accuracy.

Site visits were conducted weekly, during which the optical windows of the analyzers were cleaned with a soap solution and weak (1 percent) hydrochloric acid (HCL), and data were exported from the analyzers manually using a laptop and flash drive. A site visit log was kept to record site conditions, calibration verification checks, and the analyzers' precleaning and postcleaning nitrate measurements. During the site visits, discrete samples were collected at the deployment depth (11 ft) using a Van Dorn water sampler, and were analyzed by the Direct UV method on a Shimadzu UV1800 bench top spectrophotometer. Splits of the reference samples were also sent to the USGS National Water Quality Laboratory (NWQL) in Denver, Colorado, for comparison testing and were analyzed by NEMI method I-2548-11 with a reporting limit of $0.01 \mathrm{mg}-\mathrm{N} / \mathrm{L}$. A comparison of data by the two methods revealed a positive bias of approximately $0.25 \mathrm{mg}-\mathrm{N} / \mathrm{L}$ in the Direct UV method. The NWQL enzymereduction colorimetric method is designed to remove interferences, such as colored dissolved organic matter (CDOM) or metals during the preparation of the samples. There is no sample preparation for the Direct UV method. The Direct UV method compensates for most interfering compounds by using wavelength subtraction or through the second derivative method; therefore, the $0.25 \mathrm{mg}-\mathrm{N} / \mathrm{L}$ difference between the two methods was most likely due to matrix interference.

To compensate for matrix interferences affecting the Direct UV method, a matrix spike was employed to serve as the evaluation reference sample. The U.S Environmental Protection Agency (EPA) Forum on Environmental Measurements (FEM) defines a matrix spike as an "environmental sample to which known quantities of the target analytes are added in the laboratory (Forum on Environmental Measurements, 2010)." The volume of spiking solution should not increase the sample volume by more than 5 percent. If less than 5 percent, the volume of the spiking solution is considered insignificant, and does not need to be taken into account (Thermo Scientific, 2011). For most laboratory purposes, a matrix spike is used to demonstrate that the sample preparatory steps of the method have not adversely affected the analyte concentration (U.S Environmental Protection Agency, 2004). In this case, the matrix spike was used to adjust for the unpredictable effect that site matrix interferences have on the Direct UV method. To prepare the matrix spike, the grab sample was filtered through a Pall 0.45 -micron $(\mu \mathrm{m})$ filter to remove particulates. This filtered water was used to fill to the meniscus of a Class A 100 milliliter (mL) volumetric flask containing $0.5 \mathrm{~mL}$ of a $1,000 \mathrm{mg}-\mathrm{N} / \mathrm{L}$ nitrate standard. The spike or "known quantity of target analyte" concentration used in this evaluation was $5 \mathrm{mg}-\mathrm{N} / \mathrm{L}$, and was calculated using the following formula:

$$
\mathrm{X}=(\mathrm{Cn} * \operatorname{Vn}) /(\mathrm{Cs})
$$

where

$\mathrm{X}=\quad$ volume of nitrate stock standard to be diluted in $\mathrm{mL}$

$\mathrm{Cn}=\quad$ desired concentration of the matrix spike in $\mathrm{mg} / \mathrm{L}$

$\mathrm{Vn}=$ desired volume of matrix spike in $\mathrm{mL}$, and

$\mathrm{Cs}=\quad$ concentration of the spiking solution in $\mathrm{mg} / \mathrm{L}$. 
To prepare $100 \mathrm{~mL}$ of a $5 \mathrm{mg} / \mathrm{L}$ matrix spike from a $1,000 \mathrm{mg} / \mathrm{L}$ nitrate stock solution, the volume of the stock nitrate solution to be diluted in the filtered river water is

$$
\mathrm{X}=(5 \mathrm{mg} / \mathrm{L} * 100 \mathrm{~mL}) /(1000 \mathrm{mg} / \mathrm{L})=0.5 \mathrm{~mL} .
$$

The final concentration of the raw discrete (reference) samples from the matrix spike was calculated using the following formula:

$$
\text { C_reference }=\text { C_(matrix spike) }- \text { C_spike, }
$$

where

$$
\begin{aligned}
& \text { C_reference }= \begin{array}{l}
\text { reference sample concentration in mg-N/L } \\
\text { C_(matrix spike })=
\end{array} \\
& \text { measured concentration of the spiked sample in mg-N/L }(\text { discrete sample }+5 \mathrm{mg}-\mathrm{N} / \mathrm{L}) ; \text { and } \\
& \text { known concentration of the added spike in mg-N/L }(5 \mathrm{mg}-\mathrm{N} / \mathrm{L}) .
\end{aligned}
$$

This value was compared to the raw (unspiked) filtered river water measurements, and on average was $0.24 \mathrm{mg}-\mathrm{N} / \mathrm{L}$ lower in concentration. The matrix spike compensated for stubborn interferences like color and eliminated the high bias caused from the interference. The difference in concentration was similar to the concentration difference seen between the Direct UV measurement and the reduction method and validated the theory of measurement interference contribution. Analyzer accuracy was determined by the differences between the measured values to the C_reference standards.

\section{New Jersey}

In October 2012, the HIF partnered with the USGS New Jersey (NJ) Water Science Center (WSC) to deploy the analyzers at USGS site 01389005 Passaic River below Pompton River at Two Bridges, N.J. (fig. 11). The station is located $400 \mathrm{ft}$ downstream from the mouth of the Pompton River, on the left bank of the Passaic River.

The upper Passaic River travels through suburban New Jersey and empties the Great Piece Meadow Swampland. The upper Passaic River has a highly circuitous route and normally has higher nitrate concentrations than the Pompton River. The Pompton River drains several reservoirs upstream from the USGS site, and tends to have a green hue from algal growth during the warm season. The water at the convergence of these two rivers is poorly mixed and creates two distinct water matrices. A system of three pumps collects sample water from the Passaic River (right intake), the Pompton River (left intake), and either the Passaic or Pompton Rivers, depending on the relative amounts of stream flow (middle intake). Only measurements made of water from the right and left intakes were used in this evaluation. At Two Bridges, the Hach NITRATAX (5 mm), TriOS ProPs $(10 \mathrm{~mm})$, and Satlantic SUNA $(10 \mathrm{~mm})$ from Phase I were operated in conjunction with an existing S::CAN Spectro::lyser $(35 \mathrm{~mm}$ ) operated by the NJWSC as part of its continuous monitoring program (fig. 12).

The four analyzers and a YSI model 6920 multiparameter sonde were installed in an open basin in the gage house. At scheduled intervals, the basin was automatically and sequentially filled with water from each of the three intakes. The waterquality sensor and the nitrate analyzers measured the characteristics of water pumped sequentially from the three separate intakes. Site conditions, including gage height, temperature, specific conductance, $\mathrm{pH}$, dissolved oxygen, turbidity, and dissolved organic carbon (DOC), were also monitored for each intake. A deionized (DI) water wash was used to automatically clean the analyzer windows of the TriOS, S::CAN, and SUNA, and the Hach's integrated wiper was used to clean its optical window. Three of the analyzers - the TriOS, Hach, and SUNA - measured nitrate using their stock calibrations. The S::CAN at the beginning of the deployment was on loan from the manufacturer while the NJWSC-owned unit was being repaired. The S::CAN also had a stock calibration. This loaner unit was replaced on October 22, 2012, with one equipped with a manufacturer-developed, custom calibration for the local site conditions.

The S::CAN and water-quality monitor data were collected and transmitted by the NJWSC-owned data logger. A WaterLOG ${ }^{\circledR} \mathrm{H}-522+$ data collection platform (DCP) was installed and used to collect and transmit data from the TriOS, Hach, and SUNA over the Geostationary Operational Environmental Satellite (GOES). The SUNA is SDI-12 compliant and was directly connected to the DCP. A computer with Windows XP was used to interface the DCP with the TriOS and Hach analyzers. The TriOS controller was connected to the computer using Modbus over TCP/IP through an Ethernet cable and the Hach's sc controller was connected to the computer using an RS-232/RS-485, Modbus to serial converter. Data from the TriOS and the Hach were written by the computer into unused memory locations in the DCP using Labview, and the DCP was set up to transmit the memory locations as two of its measurements. The S::CAN and the water-quality sonde were programmed to sample each intake hourly. The DCP retrieved the data from the TriOS, Hach, and SUNA analyzers every 6 minutes, and transmitted the previous 10 measurements from each analyzer hourly along with the battery voltage. The DCP and the SUNA were powered by a 12-volt (V) 
Results from Laboratory and Field Testing of Nitrate Measuring Spectrophotometers

battery in the gage house, and the TriOS, Hach, and S::CAN were powered by alternating current (AC). Data from the NJWSC S::CAN are usually corrected prior to being disseminated based on a regression analysis of collected water samples, which relate a NWQL-determined concentration to the in situ S::CAN-determined concentration. For the evaluation analysis, the S::CAN's data were used "raw" without this correction.

Between October and December 2012, 22 discrete samples were collected-11 each from the Passaic and the Pompton Rivers - and were analyzed by NEMI method I-2548-11 at the NWQL. These samples were collected during biweekly site visits by the NJWSC staff and on alternating weeks by cooperators from the Passaic Water Valley Commission. During site visits conducted by the NJWSC staff, the analyzers' optical windows were cleaned with a soap solution and 1-percent HCL. Fouling checks were conducted by plugging and filling the basin with water from the left intake (Pompton River), and a site visit log was kept to record the results and the site conditions.

\section{Illinois}

In April 2013, the HIF partnered with the USGS Illinois (IL) WSC to test the performance of the analyzers at USGS site 05579610 Kickapoo Creek at 2100E Road near Bloomington, Ill., a site with high nitrate concentrations. For this deployment, the HIF supplied the TriOS ProPs (10 mm) and S::CAN Spectro::lyser $(5 \mathrm{~mm})$ from Phase I, and a Satlantic SUNA V2 $(5 \mathrm{~mm})$, that were operated in conjunction with the ILWSC-owned Hach NITRATAX plus sc with a 2-mm optical path length. Gage height and discharge were recorded at the site as part of the ILWSC continuous monitoring program. No other water parameters were monitored at the site during the deployment.

USGS site 05579610 is located approximately 6 miles southeast of the city of Bloomington, and receives waters from two tributaries. The northern tributary runs along the east side of the city of Bloomington and drains subdivisions and a portion of the Central Illinois Regional Airport. The eastern tributary consists primarily of runoff from the surrounding agricultural fields (fig. 13).

In 2007, the city of Bloomington was awarded a \$950,000 EPA grant to implement several strategies to control nonpoint source pollution, including sediment and nutrients, along Kickapoo Creek in McLean County, Ill. A residential development in Bloomington, The Grove on Kickapoo Creek, was constructed in conjunction with the restoration project (fig. 14). The project, which consisted of a large-scale restoration of approximately 2,800 linear $\mathrm{ft}$ of Kickapoo Creek and approximately 40 acres of the adjacent floodplain, provided an opportunity to identify the impacts that a residential development might have on an agricultural watershed.

The four analyzers were deployed at the Kickapoo Creek restoration project in separate PVC pipes that were anchored to the creek bank and further secured with rip-rap rock (fig. 15). Three 4-in.-diameter schedule 40 PVC pipes were used for the Hach, TriOS, and the S::CAN. The SUNA V2 was too large for a standard 4-in. schedule 40 PVC pipe, and required an 8-in.diameter pipe. The controllers for the Hach, TriOS, and S::CAN were mounted in the adjacent gage house. The SUNA is SDI-12 compliant and does not come equipped with a separate controller.

Fouling of the SUNA V2 was controlled by the integrated Hydro-Wiper, which cleaned the SUNA V2 5-mm path length prior to every measurement. The Hach was programmed to engage its wiper twice an hour to combat fouling, and the TriOS and the S::CAN used an hourly air blast supplied by an external air compressor to clean the optical windows.

The Hach was programmed to sample hourly. Data were collected and transmitted by the ILWSC-owned data logger, and was retrieved through the USGS National Water Information System (NWIS) Web site at http://waterdata.usgs.gov/il/nwis/ uv/?site_no=05579610. Similar to the New Jersey deployment, a WaterLOG ${ }^{\circledR}$ H-522+ DCP was installed and used to collect and transmit data from the SUNA, TriOS, and S::CAN over GOES. A computer with Windows XP was used to interface the HIF-supplied DCP with the TriOS and S::CAN analyzers. The SUNA V2 was directly connected to the DCP. The TriOS controller was interfaced to the computer using Modbus over TCP/IP through an Ethernet cable, and the S::CAN's controller was connected to the computer through a serial port using an Instrumental Solutions Inc. (ISI) MS1-2150 Modbus/SDI-12 Protocol Converter. The converter operates as a Modbus "master"/SDI-12 "slave" to make Modbus data available as SDI-12 (Instrumental Solutions Incorporated, 2011). More information on the MS1-2150 is available at the Instrumental Solutions Inc. Web site: http://isidev.net/products. Data from the TriOS and the S::CAN were written into unused memory locations in the DCP using Labview, and the DCP was set up to transmit the memory locations as two of its measurements. The DCP read all three analyzers every 6 minutes, and transmitted the data once an hour. Both DCPs and the SUNA were powered by a 12-V battery in the gage house, and the TriOS, Hach, and S::CAN ran on AC power.

Reference samples were collected between April and July 2013, and analyzed by NEMI method I-2548-11 at the NWQL. During site visits, the analyzers' optical windows were cleaned with a soap solution and site conditions with preclean and postclean nitrate measurements were recorded. 


\section{Phase II Test Results}

\section{Mississippi - Low Nitrate Concentration}

Continuous nitrate data for the four analyzers were evaluated for the following site conditions - gage height, stream velocity, temperature, turbidity, and specific conductance (fig. 16). Initially, the Hach and the S::CAN's controllers were erroneously programmed to record data every 60 seconds, which resulted in a data file too large to be preserved and deletion of 2 weeks of the initial data before the measurement interval was corrected. A site log recorded the analyzers' weekly nitrate results at the time that discrete samples were collected. The performances of the Hach and the S::CAN were evaluated by the difference between the analyzers' log values and the discrete sample concentration on the days the continuous data were missing. The 3-week gap in the TriOS data was due to a faulty installation. At 4.9 kilograms $(\mathrm{kg})$, the TriOS was the heaviest of the four analyzers. The TriOS was deployed in such a way that the body of the TriOS was not sufficiently supported, which put a strain on the communication cable. The cable failed on March 30,2012, and a replacement cable was not obtained for approximately 3 weeks. As mentioned earlier, the SUNA's integration period was reduced (March 20, 2012) and the S::CAN's calibration was adjusted twice (March 6, 2012, and April 3, 2012). These changes to the instrument settings are shown as blue arrows in figure 16. The values of the discrete samples that were collected and analyzed independently are plotted as red squares on the time series for the four analyzers.

Nitrate concentrations in the river did not vary dramatically during the deployment period. Concentrations ranging from less than detection ( 0 reading) to $1.87 \mathrm{mg}-\mathrm{N} / \mathrm{L}$ were recorded by the analyzers, and the discrete sample concentration ranged from $0.33-0.84 \mathrm{mg}-\mathrm{N} / \mathrm{L}$. Gage height varied from 8.84 to $14.46 \mathrm{ft}$ during the deployment, and the stream velocity ranged from a slightly negative value due to tidal influence to 3.73 feet per second (ft/s). Specific conductance was recorded with a maximum value of 102 microseimens per centimeter $(\mu \mathrm{S} / \mathrm{cm})$. Water temperature varied from 14.0 to $27.2{ }^{\circ} \mathrm{C}$. Although low for the majority of the deployment time, turbidity increased temporarily to a maximum of 667 formazin nephelometric units (FNU) after a local storm; and although unmonitored, the highly colored water of the East Pearl River indicated the presence of DOC both of which can increase baseline noise at low wavelengths and cause a positive bias in measured nitrate concentration.

The Hach analyzer displayed the most accurate and consistent performance throughout the deployment. Measured nitrate concentrations from the TriOS and SUNA analyzers were consistently lower than the discrete sample concentrations. The S::CAN's measured nitrate concentration was initially higher; however, the application of the second calibration adjustment improved the S::CAN's performance. Data from the SUNA showed several zero values during the deployment, which most likely resulted from the absence of an active anti-fouling mechanism.

In late March a round of local storms produced nearly $10 \mathrm{in.} \mathrm{of} \mathrm{rain} \mathrm{in} \mathrm{a} \mathrm{48-hour} \mathrm{period.} \mathrm{River} \mathrm{conditions} \mathrm{at} \mathrm{the} \mathrm{site}$ changed in response to this event with increases in nitrate, turbidity, and stream velocity, and a decrease in specific conductance. The change in nitrate concentration was verified by the reference samples collected before and after the event, and the change was registered to varying degrees by all four analyzers. The dynamic nature of nitrate in the river during this event, even though it was over a relatively small concentration range, demonstrated the value that continuous monitoring made possible by these analyzers. Table 2 summarizes the standard and measured nitrate concentrations observed during the deployment. Nitrate concentrations of the reference samples never exceeded $1 \mathrm{mg}-\mathrm{N} / \mathrm{L}$ - a concentration range much smaller than what is found in water samples from many surface-water and groundwater sites. Turbidity increased substantially from an average of less than $100 \mathrm{FNU}$ to more than $600 \mathrm{FNU}$ after the storm, and could have contributed to the rise in nitrate concentration observed in the data from the analyzers. 
Table 2. Nitrate plus nitrite results from the East Pearl River.

[FNU, formazin nephelometric unit; mg-N/L, milligrams nitrogen per liter]

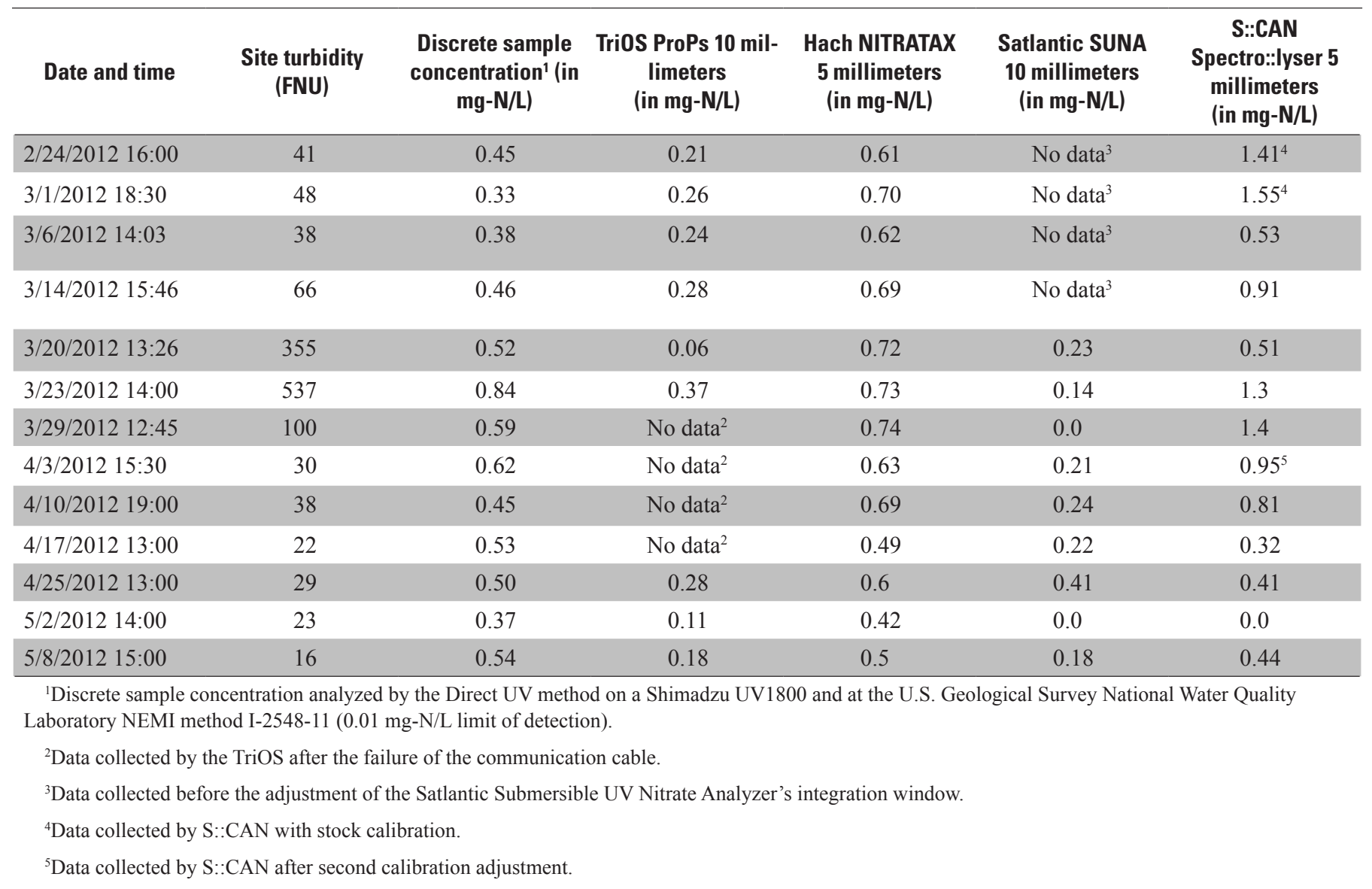

\section{New Jersey - Mid-Level Nitrate Concentration}

Continuous nitrate data for the four analyzers were evaluated for the following site conditions-gage height, temperature, turbidity, and DOC (figs. 17 and 18). The gap in the continuous data was the result of the power loss that occurred after Hurricane Sandy made landfall on October 29, 2012.

\section{Passaic River}

The nitrate concentrations of the Passaic River varied substantially during the deployment period. Measured concentrations of 0.56 to $5.2 \mathrm{mg}-\mathrm{N} / \mathrm{L}$ were recorded by the analyzers, while the reference samples ranged from 1.2 to $4.1 \mathrm{mg}-\mathrm{N} / \mathrm{L}$. Gage height was the same for both rivers and varied from 3.3 to $5.5 \mathrm{ft}$ during the deployment. The Passaic River's average turbidity was 4.0 FNU, and average DOC was $5.2 \mathrm{mg} / \mathrm{L}$. Water temperature varied from 4.5 to $16.5{ }^{\circ} \mathrm{C}$.

The Hach and the SUNA provided the most accurate and consistent data for water from the Passaic River. The Hach's reported range was 0.85 to $4.7 \mathrm{mg}-\mathrm{N} / \mathrm{L}$ with $0.15 \mathrm{mg}-\mathrm{N} / \mathrm{L}$ average absolute difference from the discrete sample concentration. The SUNA had an average absolute difference of $0.16 \mathrm{mg}-\mathrm{N} / \mathrm{L}$ and a 0.88 to $4.68 \mathrm{mg}-\mathrm{N} / \mathrm{L}$ measured nitrate range. Average absolute difference between the TriOS measurements and the discrete samples was $0.24 \mathrm{mg}-\mathrm{N} / \mathrm{L}$ in a 0.72 to $4.31 \mathrm{mg}-\mathrm{N} / \mathrm{L}$ range. The $\mathrm{S}: \mathrm{CAN}$ differed from the discrete samples an average of $0.34 \mathrm{mg}-\mathrm{N} / \mathrm{L}$ in a 0.56 to $5.16 \mathrm{mg}-\mathrm{N} / \mathrm{L}$ nitrate range. A summary of the results from the Passaic River is listed in table 3. 
Table 3. Nitrate plus nitrite results from the Passaic River.

[FNU, formazin nephelometric unit; mg-N/L, milligrams nitrogen per liter]

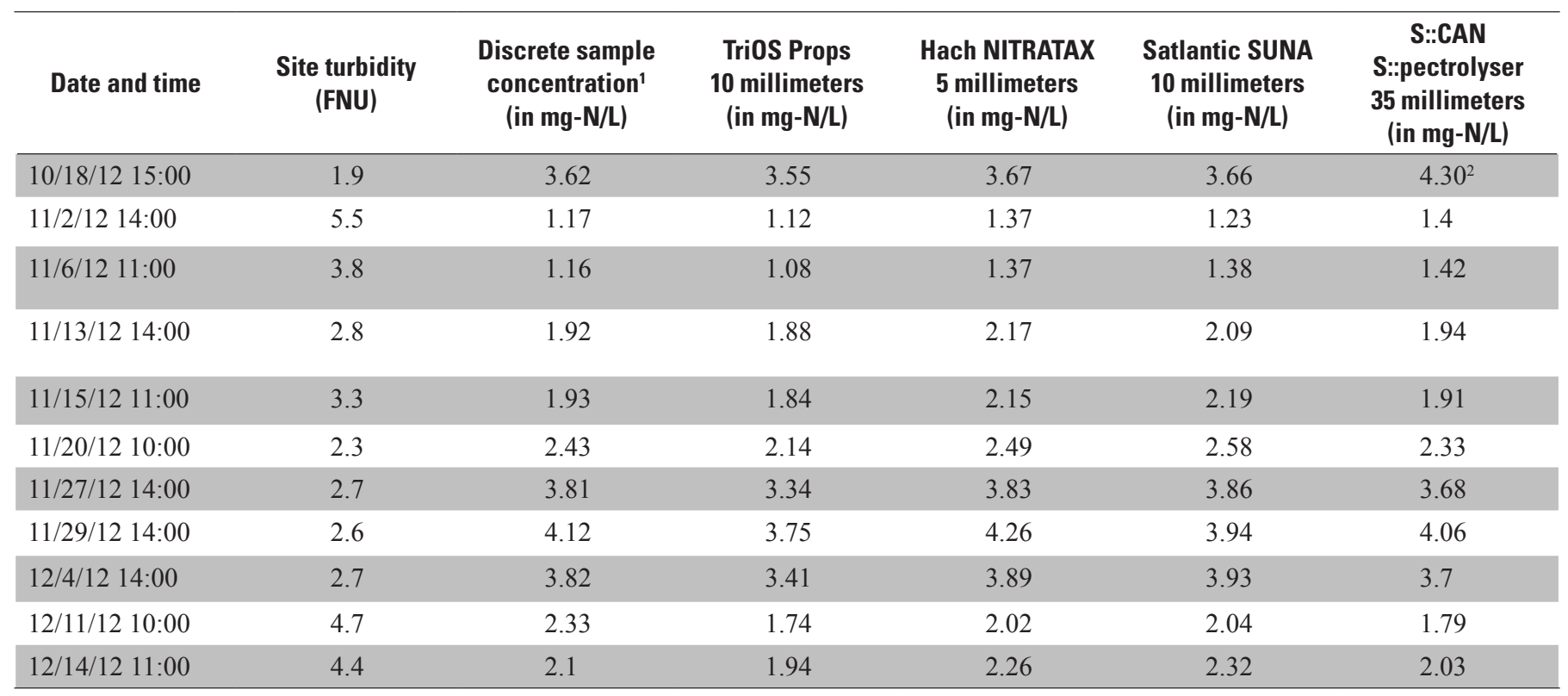

${ }^{1}$ Discrete sample concentration analyzed at the U.S. Geological Survey National Water Quality Laboratory NEMI method I-2548-11 (0.01 mg-N/L limit of detection).

${ }^{2}$ Data collected by loaner S::CAN with stock calibration.

\section{Pompton River}

For the Pompton River, the Hach, and SUNA again provided the most accurate results when compared to the discrete sample concentrations analyzed at the NWQL. During the testing period, the four analyzers measured a cumulative range of 0.38 to $3.2 \mathrm{mg}-\mathrm{N} / \mathrm{L}$. The discrete samples varied in concentration from 0.62 to $2.09 \mathrm{mg}-\mathrm{N} / \mathrm{L}$ during the testing period. Although the overall nitrate concentration of the Pompton River was lower than the Passaic River, the analyzers consistently tracked the fluctuations in concentration. Turbidity averaged 2.6 FNU in the Pompton River, and the DOC averaged $3.4 \mathrm{mg} / \mathrm{L}$. Neither interference appeared to adversely affect the analyzers' performance. The temperature of the Pompton River ranged from 4.5 to 15.1 ${ }^{\circ} \mathrm{C}$, which was $1.4{ }^{\circ} \mathrm{C}$ cooler than the highest temperature observed for the Passaic River.

The concentration range measured by the Hach was 0.72 to $3.21 \mathrm{mg}-\mathrm{N} / \mathrm{L}$, and the average absolute difference between the Hach measured values and the discrete samples was $0.08 \mathrm{mg}-\mathrm{N} / \mathrm{L}$. Early in the deployment, the SUNA's continuous data falsely showed a zero concentration that was caused from an insufficient water depth in the sample basin during the fill from the left intake. Because the SUNA's optical path length is located higher in the unit's body than the other three analyzers, a greater water depth was needed. The pump rate was adjusted to increase the depth in the basin, and the data recorded prior to the pump adjustment were disregarded. The removal of these data points resulted in a measured range of 0.71 to $3.2 \mathrm{mg}-\mathrm{N} / \mathrm{L}$, and an average absolute difference of $0.12 \mathrm{mg}-\mathrm{N} / \mathrm{L}$ from the discrete samples.

The TriOS had an average absolute difference of $0.18 \mathrm{mg}-\mathrm{N} / \mathrm{L}$ between the measured values and the discrete samples. The measured range during the testing period was 0.52 to $2.8 \mathrm{mg}-\mathrm{N} / \mathrm{L}$. The $\mathrm{S}: \mathrm{CAN}$ had a $0.20 \mathrm{mg}-\mathrm{N} / \mathrm{L}$ average absolute difference between the measured values and the discrete samples, and the measured range in the Pompton River was 0.38 to $2.8 \mathrm{mg}-\mathrm{N} / \mathrm{L}$. A summary of the results from the Pompton River is shown in table 4. 
Table 4. Nitrate plus nitrite results from the Pompton River.

[FNU, formazin nephelometric unit; mg-N/L, milligrams nitrogen per liter]

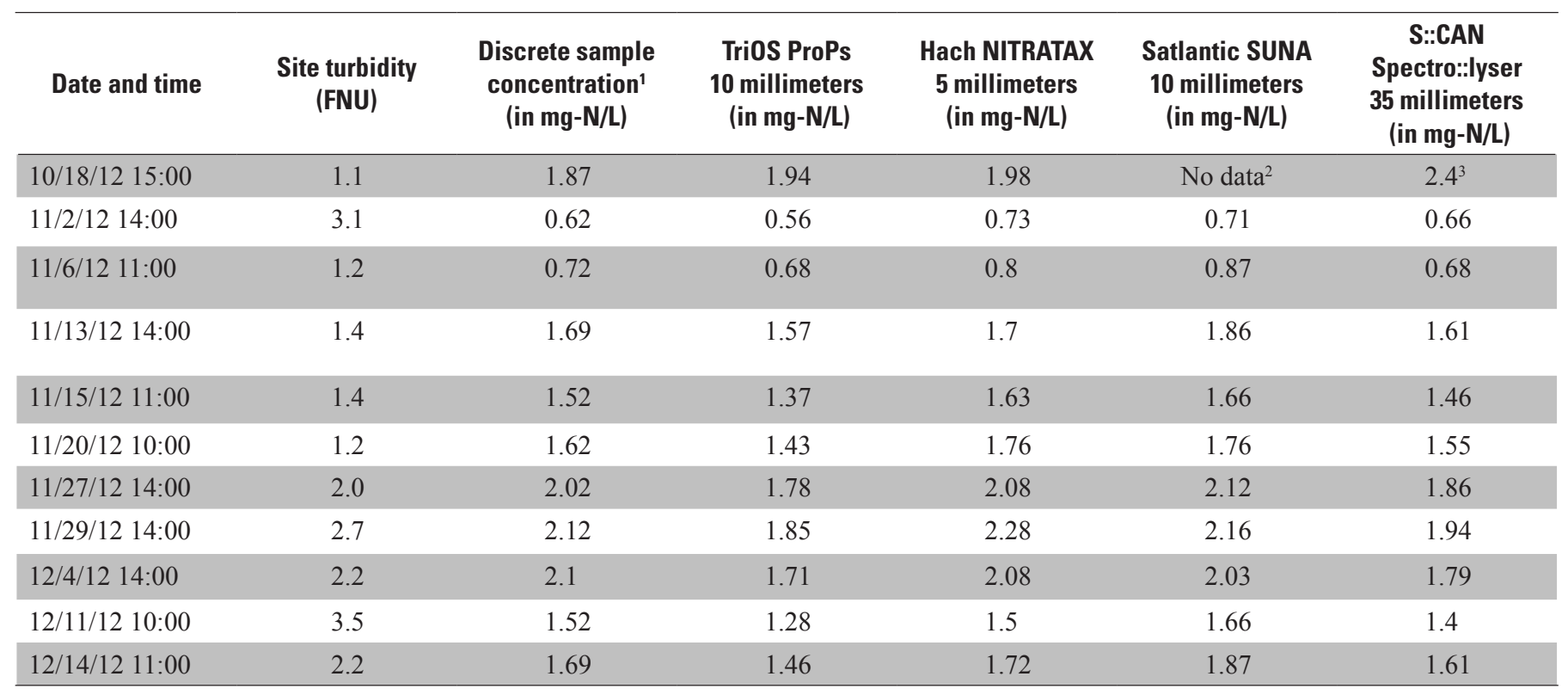

${ }^{1}$ Discrete sample concentration analyzed at the U.S. Geological Survey National Water Quality Laboratory NEMI method I-2548-11 (0.01 mg-N/L limit of detection).

${ }^{2}$ Data collected from SUNA before the adjustment of the basin water level.

${ }^{3}$ Data collected by loaner S::CAN with stock calibration.

\section{Illinois - High Nitrate Concentration}

Several problems with DCP and analyzer data transfer occurred during the Kickapoo Creek deployment, which resulted in transmittal of several weeks of erroneous values of $15.7 \mathrm{mg}-\mathrm{N} / \mathrm{L}$ for the $\mathrm{S}: \mathrm{CAN}$, and zero values for the TriOS. The correct values were recorded by the S::CAN and TriOS controllers, and were used for the data analysis for the period of the communication issue. It is theorized that issues with data transfer occurred due to an interference between the S::CAN Modbus and the TriOS controller. Continuous data from the analyzers are compared to the reference sample concentrations and two site conditionsgage height and discharge (fig. 19).

The Hach 2-mm path length provided the best performance for Kickapoo Creek. The Hach's average absolute difference between the measured values and the discrete sample concentrations was $0.16 \mathrm{mg}-\mathrm{N} / \mathrm{L}$. The range of nitrates measured by the Hach was 5.5-24.3 mg-N/L. The S::CAN had the second lowest deviation with a $2.83 \mathrm{mg}-\mathrm{N} / \mathrm{L}$ average absolute difference between the measurements and the discrete samples. The S::CAN's measured range was 4.3-23.7 mg-N/L. Average absolute difference for the TriOS was $2.91 \mathrm{mg}-\mathrm{N} / \mathrm{L}$ with a measured range of $0-32.4 \mathrm{mg}-\mathrm{N} / \mathrm{L}$. The SUNA's average difference was $3.50 \mathrm{mg}-\mathrm{N} / \mathrm{L}$ in a $0-19.1 \mathrm{mg}-\mathrm{N} / \mathrm{L}$ measured range.

The TriOS, Hach, and SUNA consistently tracked the fluctuating nitrate concentrations of Kickapoo Creek. The S::CAN data indicate a definite downward trend, possibly due to optical degradation from fouling. A local calibration adjustment to the $\mathrm{S}: \mathrm{CAN}$ in early June improved the agreement of the measured values to the discrete samples. Notably, the first three analyzers all recorded a decrease in nitrate concentration on April 17, 2012. This decrease was caused by a local storm and the resulting dilution of the creek with rainwater. Gage height and discharge both increased as a result of the precipitation. Conversely, an increase in nitrate concentration was recorded on May 30, 2012, following preciptation. Gage height and discharge also increased during this precipitation event, but the resulting precipitation fell more slowly than during the April $17^{\text {th }}$ event. The increase in the nitrate concentration of Kickapoo Creek was most likely from runoff from the surrounding agricultural fields.

Table 5 summarizes the results from the Kickapoo Creek deployment. TriOs and S::CAN data listed in the table are the measured data retrieved from the analyzers' software. The June 17, 2012, TriOS data point occurred after the catastrophic failure of the analyzer, and was not considered in the accuracy assessment. 
Table 5. Nitrate plus nitrite results from Kickapoo Creek.

[mg-N/L, milligrams nitrogen per liter]

\begin{tabular}{|c|c|c|c|c|c|}
\hline Date and time & $\begin{array}{l}\text { Discrete sample } \\
\text { concentration } \\
\text { (in mg-N/L) }\end{array}$ & $\begin{array}{l}\text { TriOS ProPs } \\
10 \text { millimeters } \\
\text { (in mg-N/L) }\end{array}$ & $\begin{array}{c}\text { Hach NITRATAX } \\
2 \text { millimeters } \\
\text { (in mg-N/L) }\end{array}$ & $\begin{array}{c}\text { Satlantic SUNA V2 } \\
5 \text { millimeters } \\
\text { (in mg-N/L) }\end{array}$ & $\begin{array}{c}\text { S::CAN Spectro::lyser } \\
5 \text { millimeters } \\
\text { (in mg-N/L) }\end{array}$ \\
\hline 4/11/13 16:00 & 22.2 & 17.62 & 22.1 & 16.4 & 20.1 \\
\hline $5 / 7 / 13 \quad 14: 20$ & 19.1 & 17.68 & 18.9 & 16.3 & 15.2 \\
\hline $5 / 21 / 1314: 10$ & 16.6 & 14.60 & 16.4 & 14.9 & 9.18 \\
\hline $6 / 17 / 1310: 40$ & 17.9 & No data ${ }^{2}$ & 18.0 & 15.5 & 17.8 \\
\hline
\end{tabular}

${ }^{1}$ Discrete sample concentration analyzed at the U.S. Geological Survey National Water Quality Laboratory NEMI method I-2548-11 (0.01 mg-N/L limit of detection).

${ }^{2}$ Data collected from TriOS after failure.

\section{Phase II Summary}

Eight analyzers with various optical path lengths from four manufacturers were evaluated in phase II: a Hach NITRATAX plus sc (5-mm path length), a Hach NITRATAX plus sc (2-mm path length), three S::CAN Spectro::lysers (5- and 35-mm path lengths), one TriOS ProPs (10-mm path length), one Satlantic SUNA (10-mm path length), and one Satlantic SUNA V2 (5-mm path length). These analyzers were placed in three different locations with low, mid-level, and high nitrate concentrations. Differences between the measured concentrations and the reference samples for all eight analyzers are compared to the discrete sample concentrations from the three deployment sites (fig. 20). Outliers, such as the data collected after the failure of the TriOS and before the fill level of the sampling tank was adjusted for the SUNA, were not included in the analysis.

The nitrate concentration of the discrete samples collected from the three sites ranged from 0.33 to $22.2 \mathrm{mg}-\mathrm{N} / \mathrm{L}$. The TriOS data (fig. 20) have an overall absolute measured difference of $0.46 \mathrm{mg}-\mathrm{N} / \mathrm{L}$ over the three-site cumulative nitrate range. The Hach results (fig. 20), which included data from two analyzers, the 5-mm and the 2-mm path lengths, showed good agreement with the discrete sample concentration. The combined Hach data resulted in a $0.13-\mathrm{mg}-\mathrm{N} / \mathrm{L}$ average absolute difference from the discrete samples. The SUNA results (fig. 20) consist of data from the SUNA (10-mm path length) and the SUNA V2 (5-mm path length). The S::CAN results (fig. 20) include data from the HIF-owned S::CAN (diamonds), the New Jersey "loaner" unit (squares), and the NJWSC-owned S::CAN (triangles). The New Jersey loaner unit measured data based upon its stock "global" calibration only. The HIF-owned S::CAN measured nitrate concentrations with the stock calibration only, and with a new calibration offset that was applied by the manufacturer. The NJWSC S::CAN measured data based upon a sitespecific custom calibration. The SUNA and SUNA V2 combined data produced a $0.66-\mathrm{mg}-\mathrm{N} / \mathrm{L}$ average absolute difference from the discrete samples, and data from the three different $\mathrm{S}: \mathrm{CAN}$ analyzers resulted in a $0.63-\mathrm{mg}-\mathrm{N} / \mathrm{L}$ average difference. The data collected with the Hach analyzers illustrated the effect of path length on measurement range of nitrate. The Hach with the shortest optical path length of the tested analyzers $(2 \mathrm{~mm})$ had the smallest differences at the highest nitrate concentrations in the field deployments, and the longer path length $(5 \mathrm{~mm})$ had a poor response for concentrations greater than $20 \mathrm{mg} / \mathrm{L}$ in the laboratory accuracy tests (fig. 7). In the field deployments, the two analyzers with the next shortest path length of $5 \mathrm{~mm}$ - the $S:: C A N$ and the SUNA - did not perform as well as the Hach at the higher nitrate concentrations.

Measured turbidities for the low- and mid-nitrate level sites were low except during peak flows (approximately $600 \mathrm{FNU}$ for the low-level site and $100 \mathrm{FNU}$ for the mid-level site). Based on the previous time series results (figs. 16, 17, and 18), data from these sites did not indicate any obvious effect on any unit measurements based on the changing turbidity levels. It is suspected that the high-nitrate-level site had higher suspended sediment and turbidity levels because of the agriculture land use within the basin, but no measurements were made to confirm this hypothesis. The field measurements (fig. 20) and the laboratory measurements (fig. 7) without turbidity effects had dissimilar trends over the same range of nitrate concentrations. Differences in path length may account for some of the variances in response, but optical path length alone does not determine accuracy. The largest differences between the field measurements and the laboratory measurements occurred at the higher concentrations, and may have been the result of turbidity, suspended sediment, and dissolved organic matter effects, in addition to the likely existence of a decreasing response to higher absorbance associated with high nitrate concentration (that is, a nonlinear response).

The statistical distribution of the measured-to-reference differences from figure 20 is shown in figure 21 and table 6 . 
Results from Laboratory and Field Testing of Nitrate Measuring Spectrophotometers

Table 6. Statistical distribution of the analyzer model's accuracy in milligrams nitrogen per liter.

\begin{tabular}{lccccccc}
\hline \multicolumn{1}{|c}{ Statistic } & $\begin{array}{c}\text { TriOS ProPs } \\
\text { (10 millimeters) }\end{array}$ & $\begin{array}{c}\text { Hach } \\
\text { NITRATAX } \\
\text { (5 millimeters) }\end{array}$ & $\begin{array}{c}\text { Hach } \\
\text { NITRATAX } \\
\text { (2 millimeters) }\end{array}$ & $\begin{array}{c}\text { SATLANTIC } \\
\text { SUNA } \\
\text { (10 millimeters) }\end{array}$ & $\begin{array}{c}\text { SATLANTIC } \\
\text { SUNA V2 } \\
\text { (5 millimeters) }\end{array}$ & $\begin{array}{c}\text { S::CAN } \\
\text { SPECTRO::LYSER } \\
\text { (5 milllimeters) }\end{array}$ & $\begin{array}{c}\text { S::CAN } \\
\text { SPECTRO::LYSER } \\
\text { (35 millimeters) }\end{array}$ \\
\hline Median & -0.21 & 0.11 & 0.00 & 0.04 & -2.89 & -0.04 & -0.09 \\
Minimum & -3.52 & -0.31 & -0.21 & -0.69 & -6.10 & -7.41 & -1.18 \\
Maximum & 0.07 & 0.37 & 0.11 & 0.26 & -1.69 & 1.22 & 0.68 \\
1st quartile & -0.38 & 0.03 & -0.19 & -0.33 & -5.39 & -0.23 & -0.25 \\
3d quartile & -0.07 & 0.18 & 0.11 & 0.14 & -2.21 & 0.32 & 0.05 \\
\hline
\end{tabular}

\section{Summary}

The recent commercial availability of UV spectrophotometers provides the opportunity to monitor nitrate concentration in situ, and thereby increase the frequency of sample analysis by eliminating the logistical constraints of discrete sampling. There are several choices available in these analyzers, with variations in detector, light source, and optical path length. Interferences like turbidity and DOC present important challenges to the analyzer design. Generally, a longer path length will increase the sensitivity of the unit and improve its ability to measure lower concentrations, but the analyzer normally will be limited more by interferences such as turbidity rather than by a shorter path length.

In this report, eight examples of five models of UV nitrate analyzers were evaluated in two phases - a controlled laboratory setting and in the field at three USGS monitoring sites. The accuracy of the analyzers was compared to NIST traceable standards and to discrete samples collected at the sites and analyzed locally using the Direct UV method, and at the USGS National Water Quality Laboratory. Measured analyzer values were collected raw, and were not corrected for fouling or calibration drift or for matrix bias. The findings of this report show how robust some sensors are against fouling, drift, and matrix bias, but in no way do these findings diminish the importance of data correction as noted in USGS protocols.

Accuracy, drift, limit of linearity (LOL), and operating temperature were tested in phase I. Accuracy requirements were met by the manufacturer (stock)-calibrated TriOS ProPs, Hach NITRATAX, and the Satlantic SUNA. The S::CAN Spectro::lyser's calibration required several adjustments before meeting the manufacturer's accuracy specifications. Instrument drift was observed in the S::CAN and was the result of insert seals leaching into the water sample. Except for the Hach, all laboratory test models met their specified LOL. The SUNA was excessively noisy and unstable in temperatures of about 20 degrees Celsius or above. Phase II tested the accuracy of the analyzers at USGS monitoring sites with low-, mid-level, and high-nitrate concentrations. In addition to varying nitrate concentrations, there were also differences in the environmental conditions and interferences, such as turbidity and DOC, at the three sites that potentially affected the performance of the analyzers.

The Hach NITRATAX $2 \mathrm{~mm}$ showed good accuracy at the Kickapoo Creek site when subjected to high sediment loads. The SUNA V2 with its 5-mm path length, although promoted to be accurate in highly turbid waters, showed a low bias relative to the discrete samples taken at Kickapoo Creek, indicating that path length alone does not ensure accuracy. Although most of the measured-to-discrete sample comparisons showed good correlation during the evaluation, deviations to the testing criteria and to the manufacturing technical specifications were found. A total of 40 discrete samples were collected from the three deployment sites and analyzed. The nitrate concentration of the samples ranged from $0.33-22.2 \mathrm{mg}-\mathrm{N} / \mathrm{L}$. The average absolute difference between the TriOS measurements and discrete samples was $0.46 \mathrm{mg}-\mathrm{N} / \mathrm{L}$. For the combined data from the Hach 5-mm and 2-mm analyzers, the average absolute difference between the Hach and the discrete samples was $0.13 \mathrm{mg}-\mathrm{N} / \mathrm{L}$. The SUNA and SUNA V2 combined data resulted in an average absolute difference of $0.66 \mathrm{mg}-\mathrm{N} / \mathrm{L}$, and the combined data from the three different S::CANs resulted in a $0.63-\mathrm{mg}-\mathrm{N} / \mathrm{L}$ average absolute difference from the discrete samples. The results of this study show the value of in situ testing for nitrates. The results also can offer insight to the user when selecting the appropriate analyzer for an application, and can assist manufacturers in improving the performance of the analyzers tested — not only in a laboratory setting, but in the environment as well. 


\section{Acknowledgments}

The author thanks Lisa Carper and Jacob Gibs (retired) of the USGS New Jersey Water Science Center, and Paul Terrio, Timothy Straub, and Nick Siudyla of the USGS Geological Illinois Water Science Center for their help and support in this project.

\section{References Cited}

American Public Health Association, 1989, Standard methods for the examination of water and wastewater, 17th ed.: Washington, D.C., American Public Health Association.

Comerford, Jeffrey, 2011, Application Note: Measuring baseline corrected spectra on a Carey 50 Dual Beam Spectrophotometer, SI-A-1192, Mulgrave, accessed April 11, 2012, at http://www.chem.agilent.com/Library/applications/uv77.pdf.

Danaher Business System [2012a], Hach products and ordering: Hach Company Web page, accessed September 3, 2012, at http://www.hach.com.

Danaher Business System [2012b], SUNA V2 UV nitrate sensor: Satlantic Web page, accessed September 3, 2012, at http:// www.satlantic.com/suna.

Forum on Environmental Measurements Method Validation Team, Environmental Measurement Glossary of Terms, January 2010, accessed April 10, 2012, at http://epa.gov/fem/pdfs/Env_Measurement_Glossary_Final_Jan_2010.pdf.

HunterLab Inc., 2008, Application Note: Double vs. Single Beam Spectrophotometers, v. 9, no. 12, Reston, accessed April 2, 2012, at http://www.hunterlab.se/wp-content/uploads/2012/11/Double-Versus-Single-Beam-Spectrophotometers.pdf.

Instrumental Solutions Inc. Modbus/SDI-12 Protocol Converter Brochure, 2011, accessed September 4, 2013, at http://isidev. net/yahoo_site_admin/assets/docs/MS1.310131826.pdf.

McNaught, A.D., and Wilkinson, A., 1997, International Union of Pure and Applied Chemistry (IUPAC) Compendium of Chemical Terminology - the Gold Book (2d ed.): Oxford, Blackwell Scientific Publications, 48 p. [Also available at http:// goldbook.iupac.org.]

Patton, C.J., and Kryskalla, J.R., 2011, Colorimetric determination of nitrate plus nitrite in water by enzymatic reduction, automated discrete analyzer methods: U.S. Geological Survey Techniques and Methods, book 5, chap. B8, at http://pubs.usgs.gov/ $\mathrm{tm} / 05 \mathrm{~b} 08 /$.

Pellerin, B.A., Bergamaschi, B.A., Downing, B.D., Saraceno, J.F., Garrett, J.A., and Olsen, L.D., 2013, Optical techniques for the determination of nitrate in environmental waters; Guidelines for instrument selection, operation, deployment, maintenance, quality assurance, and data reporting: U.S. Geological Survey Techniques and Methods, book 1, chap. D5, 37 p., at http://pubs.usgs.gov/tm/01/d5/.

S::can messtechnik GmbH, S::can home page [2012]: S::can messtechnik GmbH Web page, accessed September 2, 2012, at http://www.s-can.us/.

Thermo Scientific, 2011, Application Note: Matrix Spiking-Why Spike and How to Do it, Log 112: Thermo Scientific, Environmental \& Process Instruments Division, accessed January 6, 2013, at www.thermoscientific.com/waterlibrary.

TriOS Mess- und Datentechnik GmbH [2012], Welcome to TriOS Optical Sensors: TriOS Mess- und Datentechnik GmbH Web page, accessed October 10, 2012, at http://trios-science.com.

U.S. Environmental Protection Agency (EPA), 2004, EPA memorandum, Assuring the Competency of Environmental Protection Agency Laboratories, accessed September 23, 2012, at http://www.epa.gov/fem/pdfs/labdirective.pdf.

Wagner, R.J., Boulger, R.W., Jr., Oblinger, C.J., and Smith, B.A., 2006, Guidelines and standard procedures for continuous water-quality monitors-Station operation, record computation, and data reporting: U.S. Geological Survey Techniques and Methods, book 1, chap. D3, 51 p. +8 attachments, at http://pubs.usgs.gov/tm/2006/tm1D3/. 


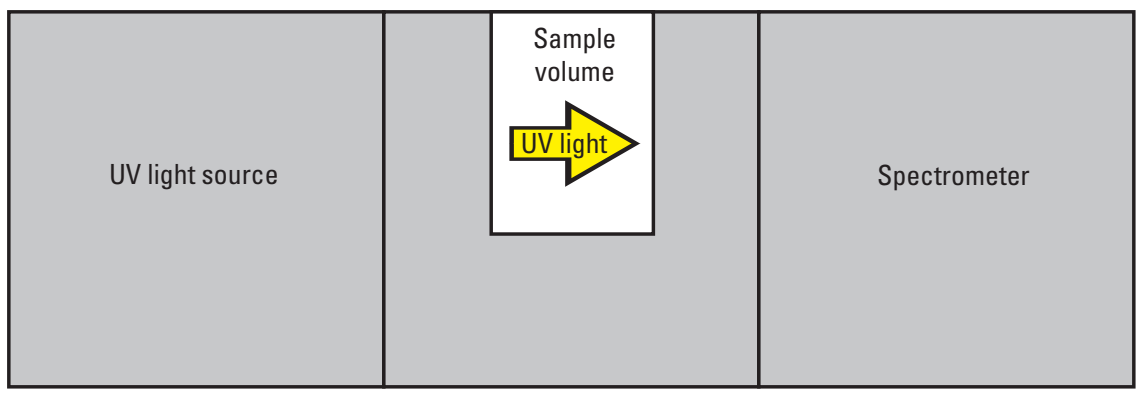

Figure 1. Schematic illustration of a spectrophotometer.
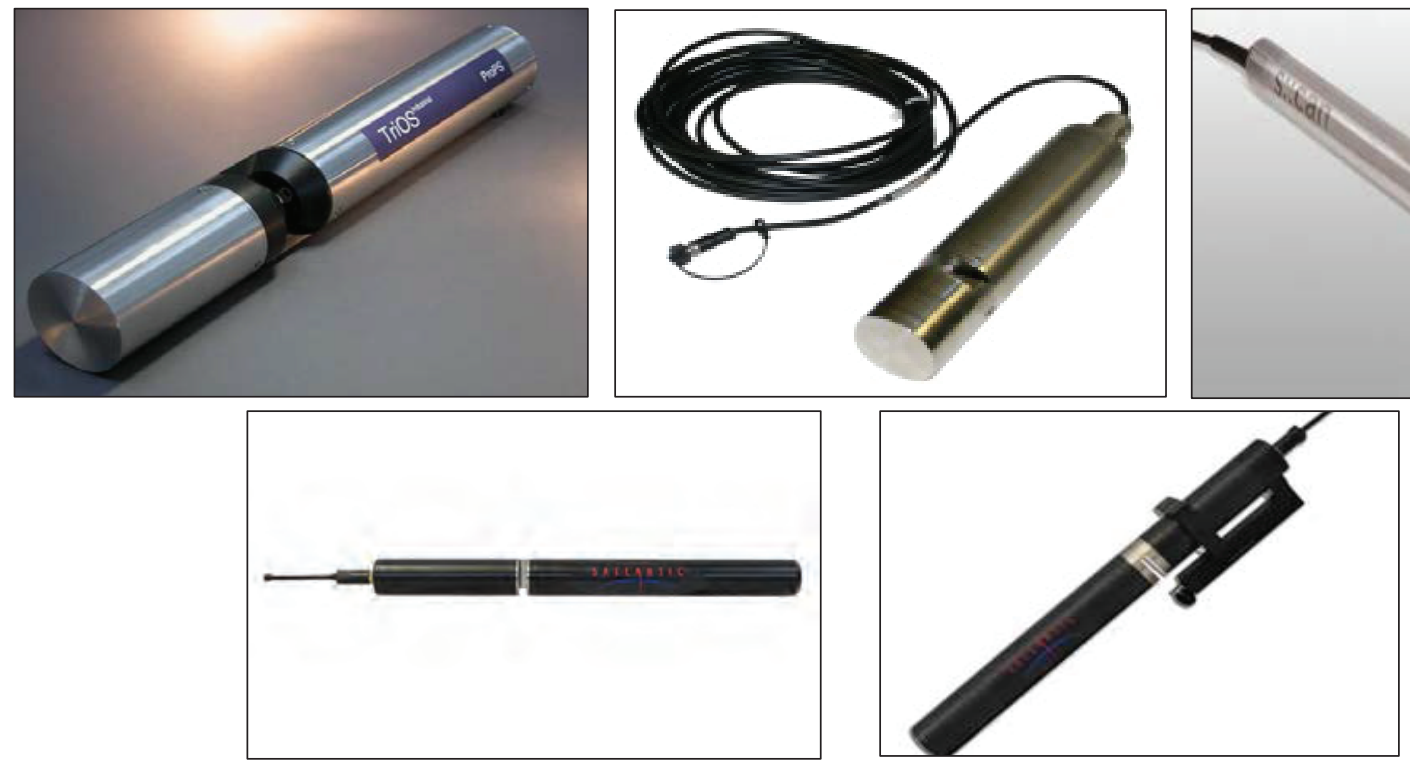

Figure 2. Photos of nitrate analyzers: TriOS ProPS, (top left); Hach NITRATAX, (top center) S::CAN Spectro::lyser (top right) Satlantic SUNA, (bottom left), and Satlantic SUNA V2 (bottom right). 


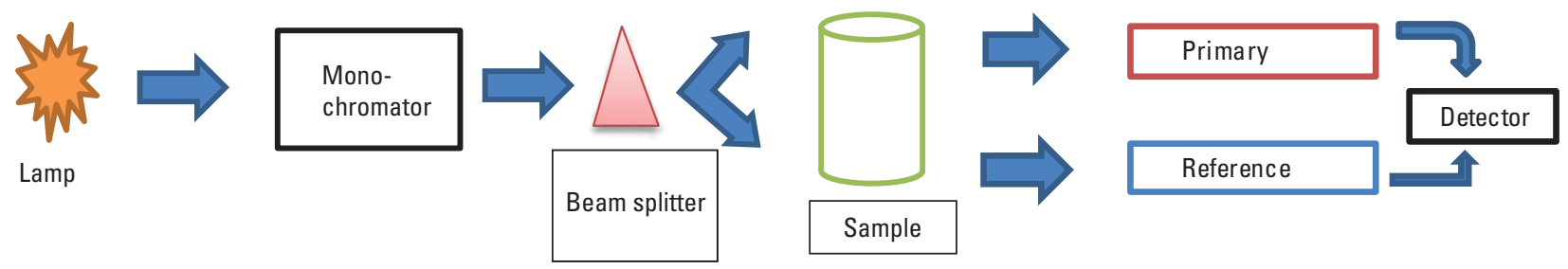

Figure 3. A schematic of a split or double-beam configuration.

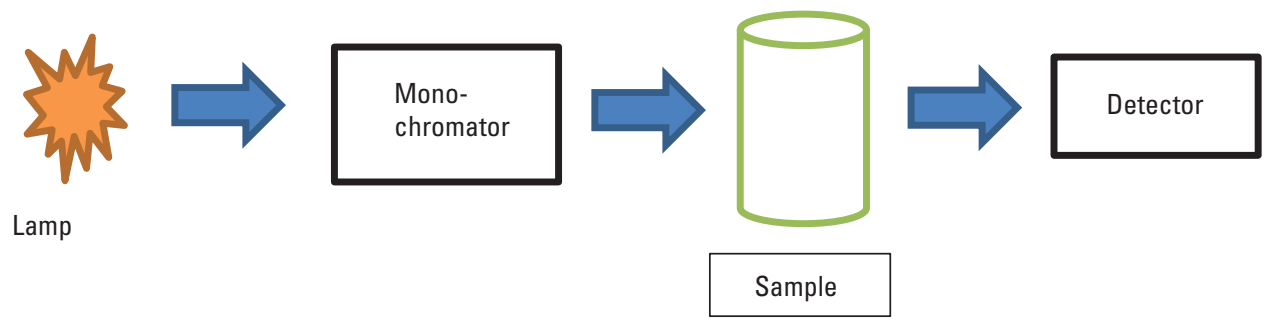

Figure 4. A schematic of a single-beam configuration.

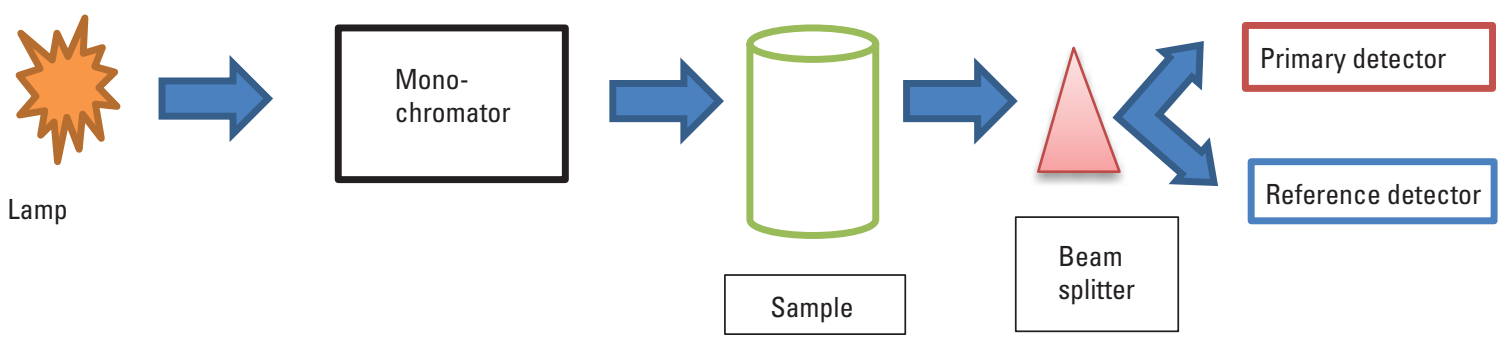

Figure 5. A schematic of a dual-beam configuration. 


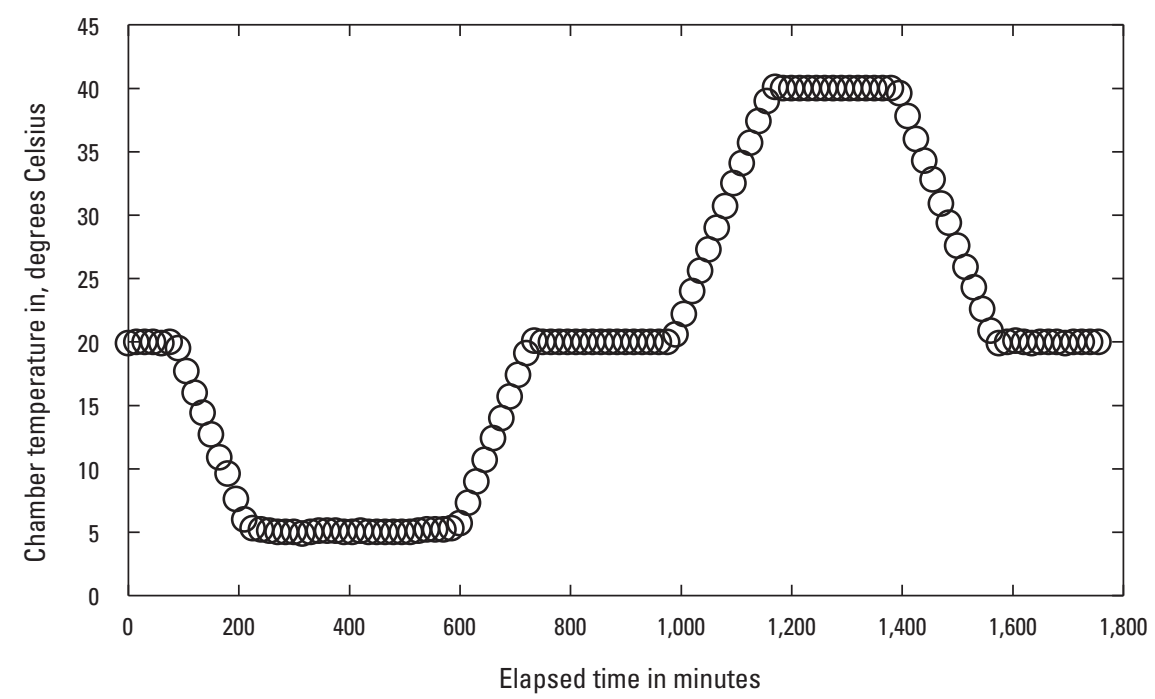

Figure 6. Temperatures applied during temperature testing for nitrate analyzers.
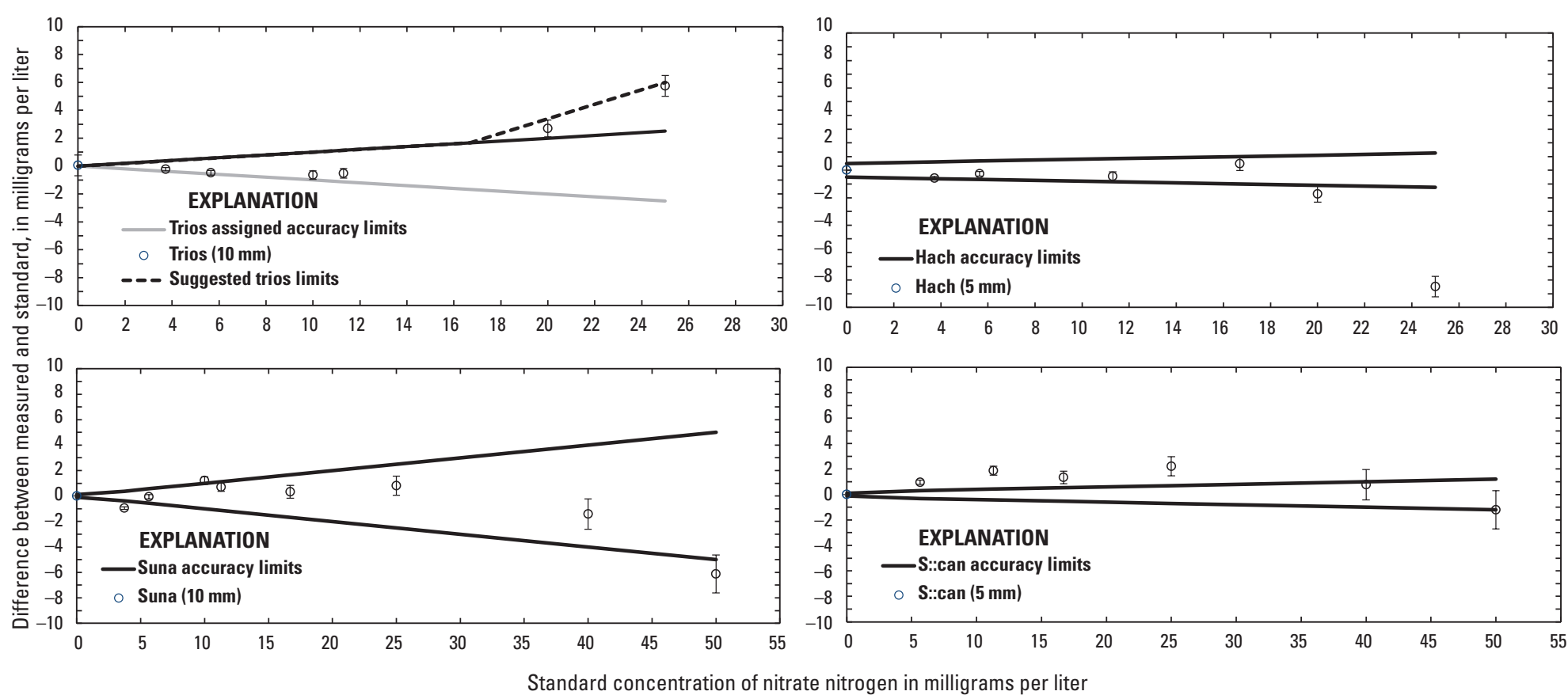

Figure 7. Accuracy results for TriOS (top left), Hach (top right), SUNA (bottom left), and S::CAN (bottom right) ultraviolet nitrate analyzers. Error bars represent the estimated uncertainty, \pm 3 percent, of the standard concentration. 

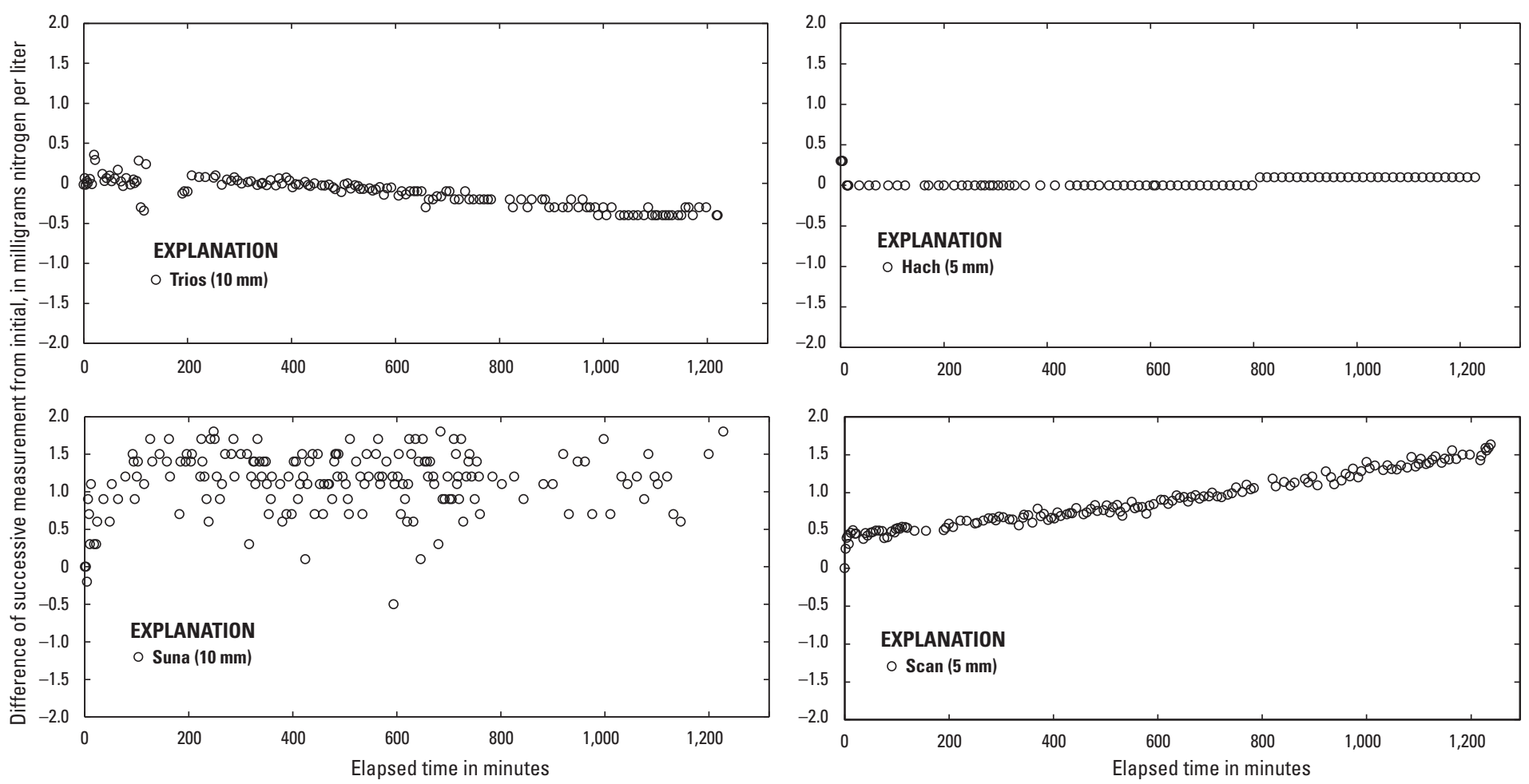

Figure 8. Drift results for TriOS (top left), Hach (top right), SUNA (bottom left), and S::CAN (bottom right) ultraviolet nitrate analyzers. Plotted is the difference in successive measurements from the initial measurement over time.
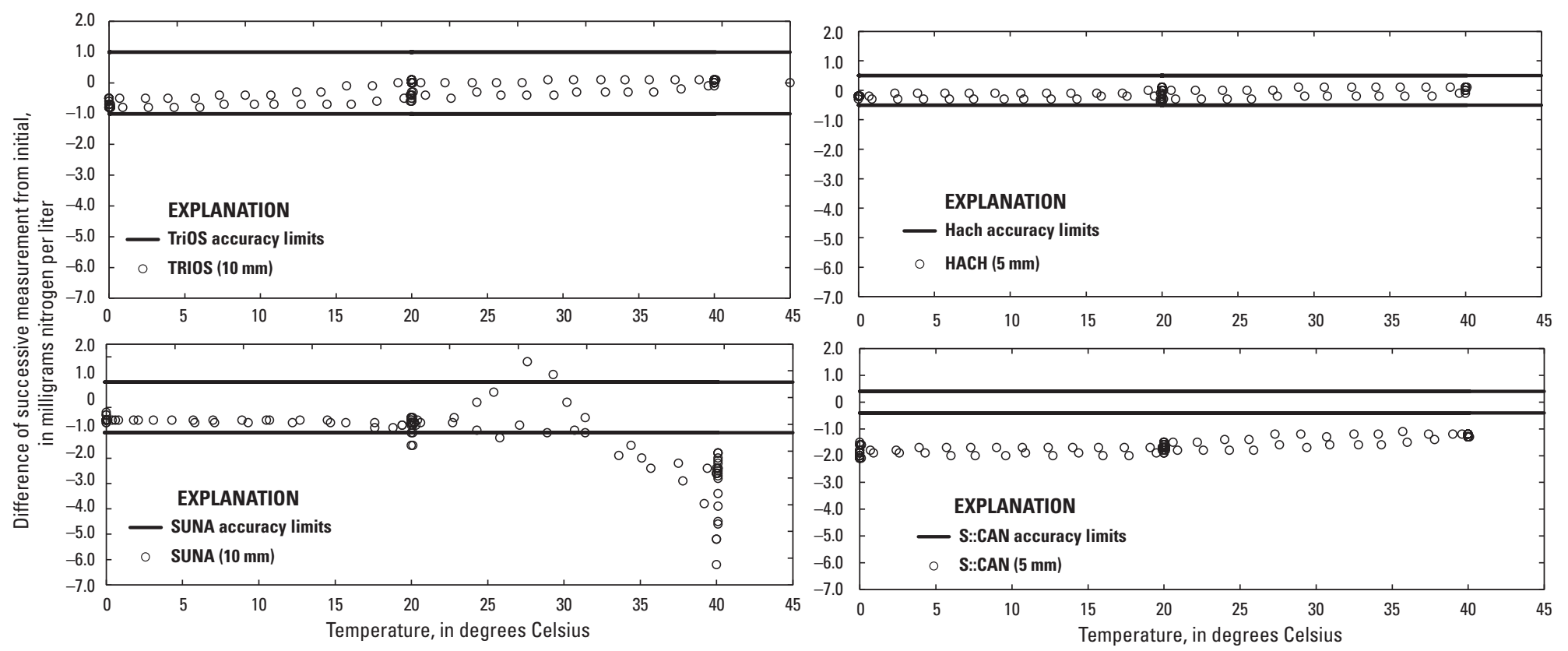

Figure 9. The difference between measured nitrate and standard concentration over an extended temperature range, for TriOS (top left), and Hach (top right), SUNA (bottom left), and S::CAN (bottom right). 

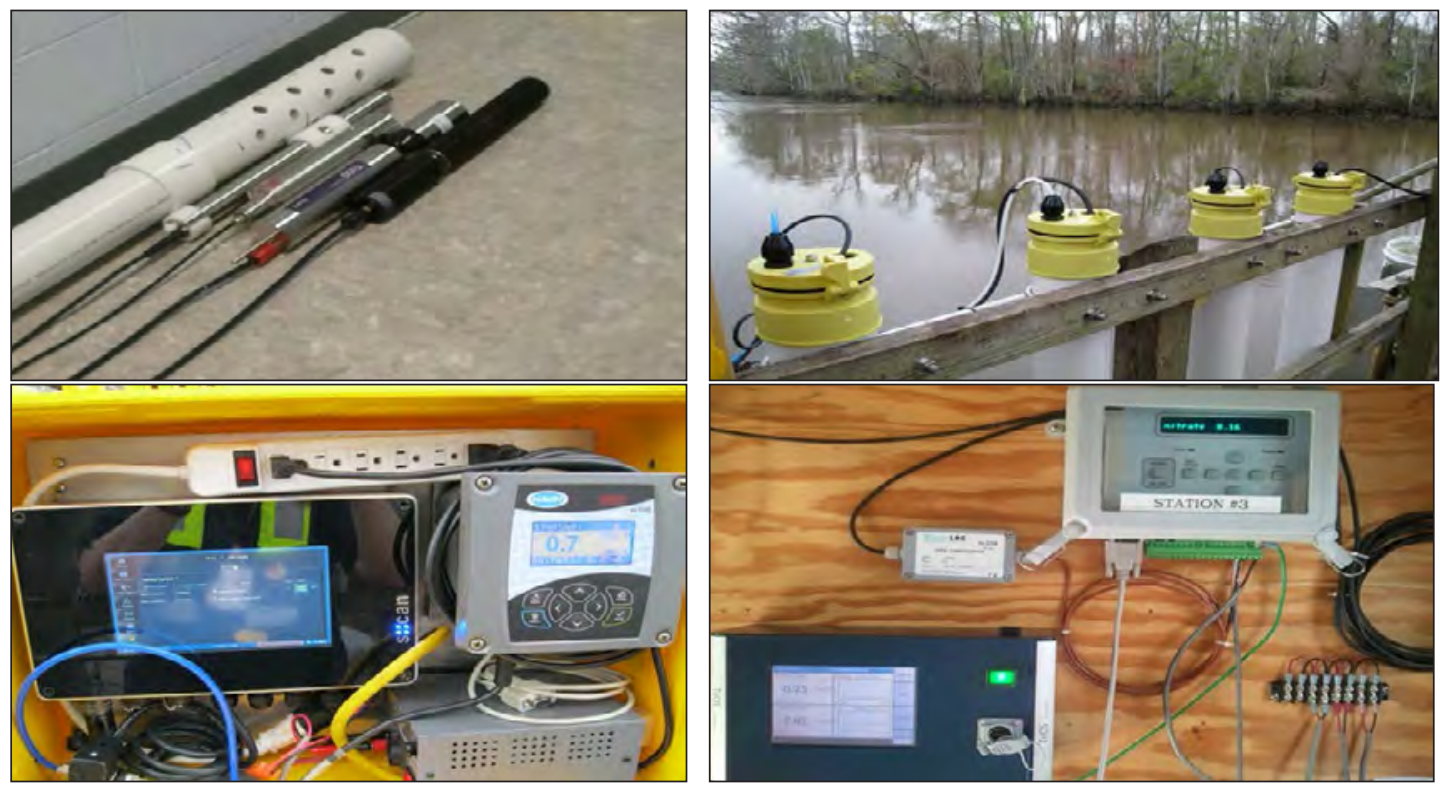

Figure 10. Top left, (left to right) the S::CAN, Hach, TriOS, and SUNA analyzers next to an uninstalled deployment pipe. Top right, installed deployment pipes at the test pier. Bottom left, the S::CAN and Hach controllers, bottom right, the TriOS Tribox controller and the WaterLog H-500XL data logger interfaced with the SUNA.

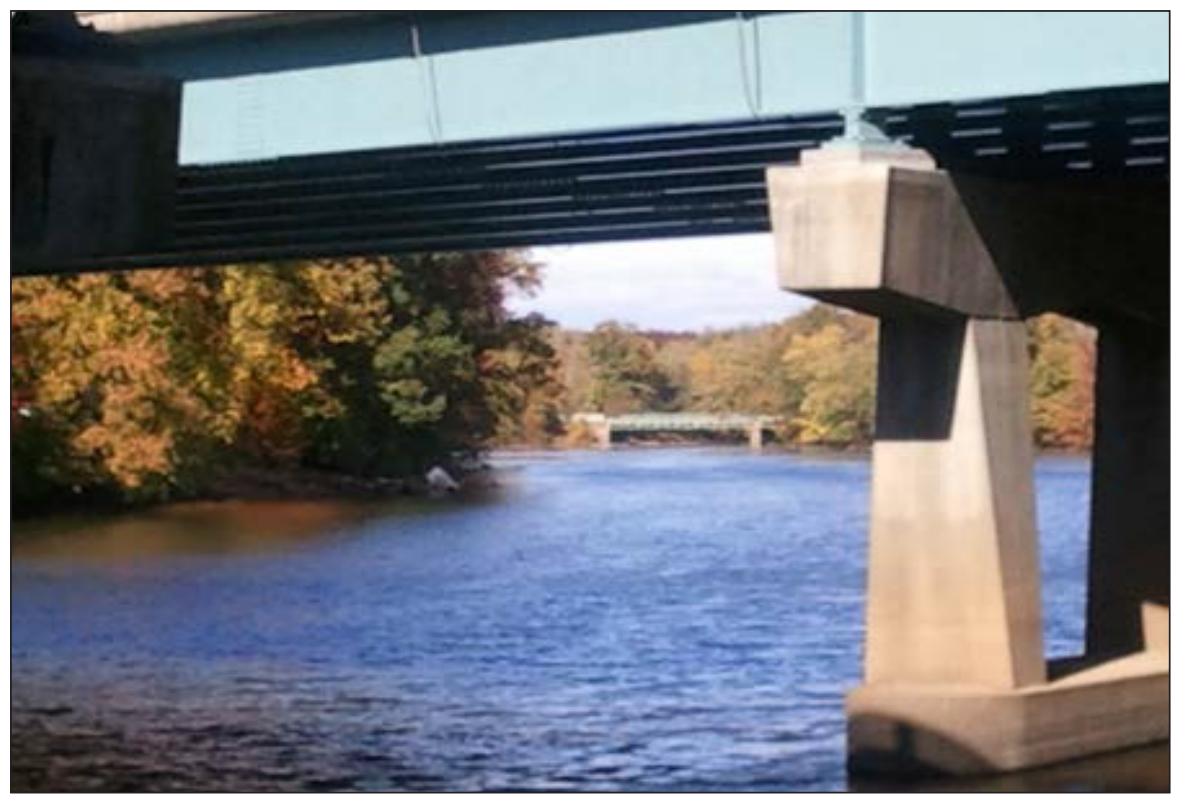

Figure 11. Two Bridges, New Jersey. View is looking downstream from the gage house. 


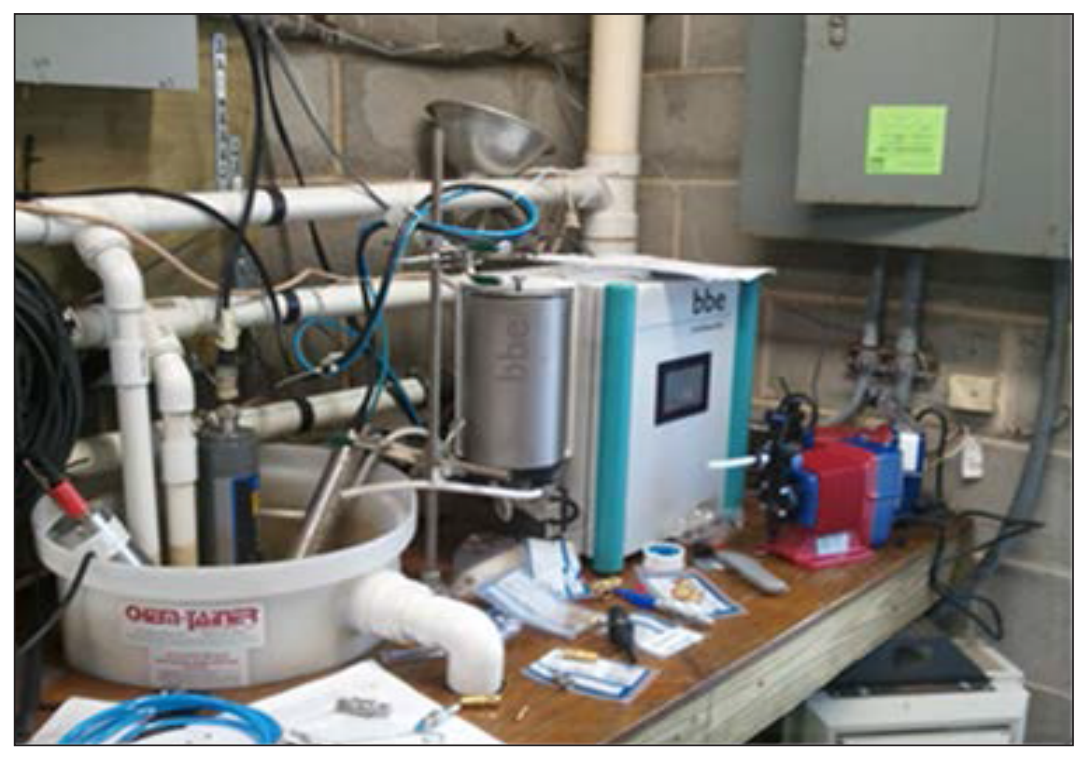

Figure 12. Two Bridges sampling system. Pictured on the left is the open basin that was sequentially filled with water from the three intakes. A fluorometer is located right of the basin.

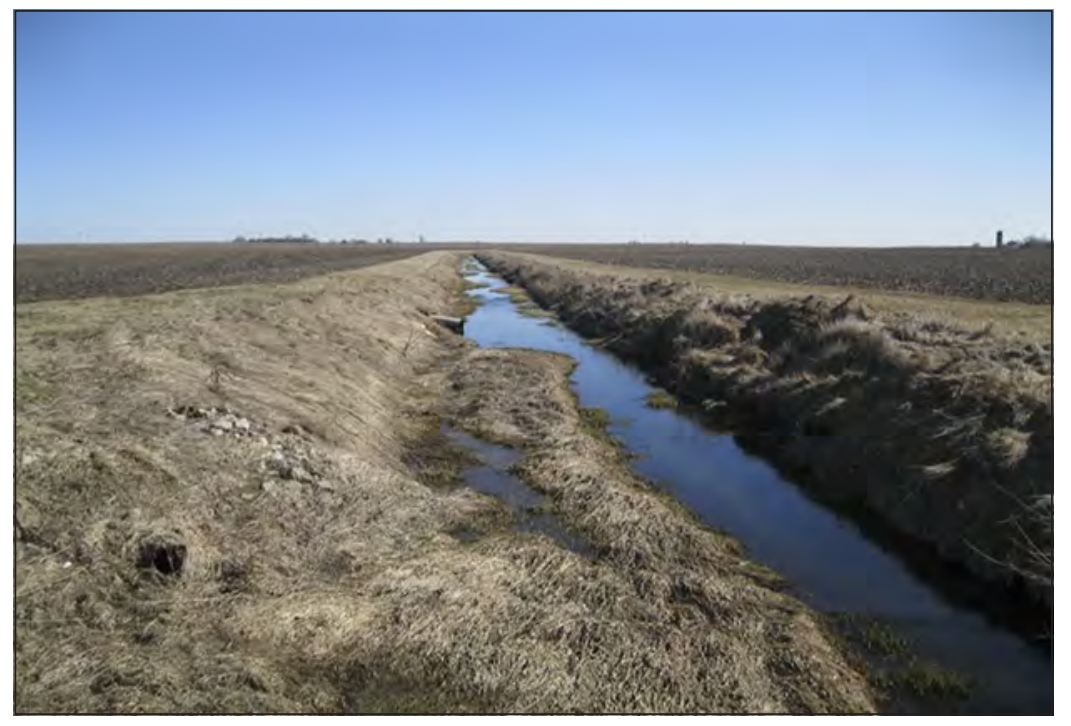

Figure 13. Agricultural fields surrounding Kickapoo Creek. 


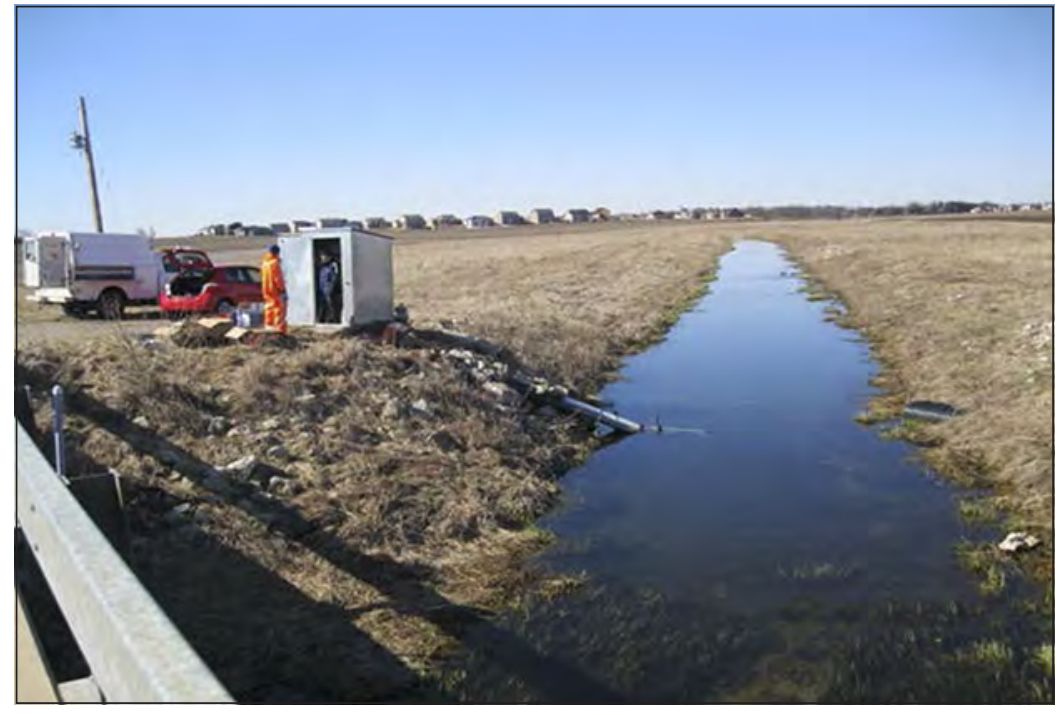

Figure 14. Site of Kickapoo Creek restoration project including The Grove subdivision seen in the background.

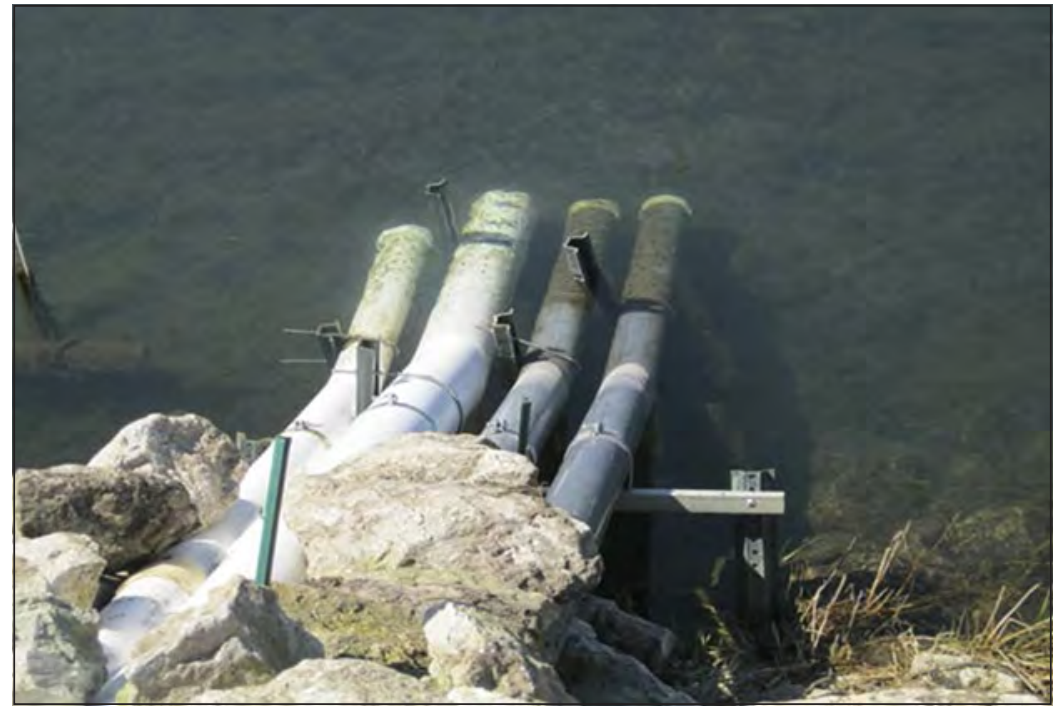

Figure 15. Installation of the nitrate analyzers at USGS site 05579610, Bloomington, Illinois. 

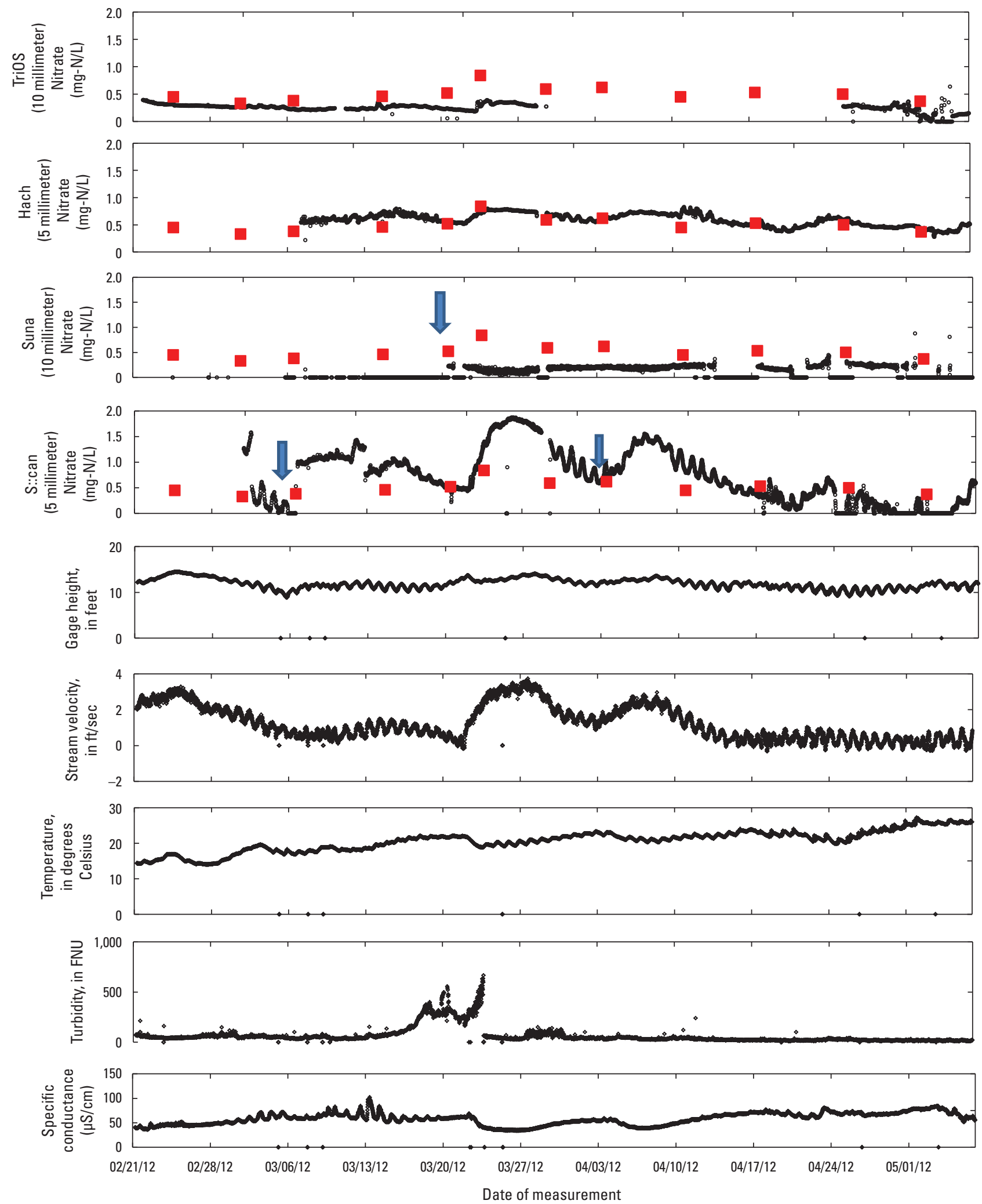

Figure 16. Stacked time series plots for measured nitrate concentration in milligrams nitrogen per liter (mg-N/L) plotted for the East Pearl River gage height in feet, stream velocity in feet per second (ft/sec), temperature in degrees Celsius, turbidity in formazin nephelometric units (FNU), and specific conductance in microseimens per centimeter $(\mu \mathrm{s} / \mathrm{cm})$. Red boxes represent the reference samples collected from the East Pearl River during the testing period and the blue arrows denote the reduction in the Satlantic Submersible UV Nitrate Analyzer's integration window and the two local adjustments of the S::CAN's calibration. 

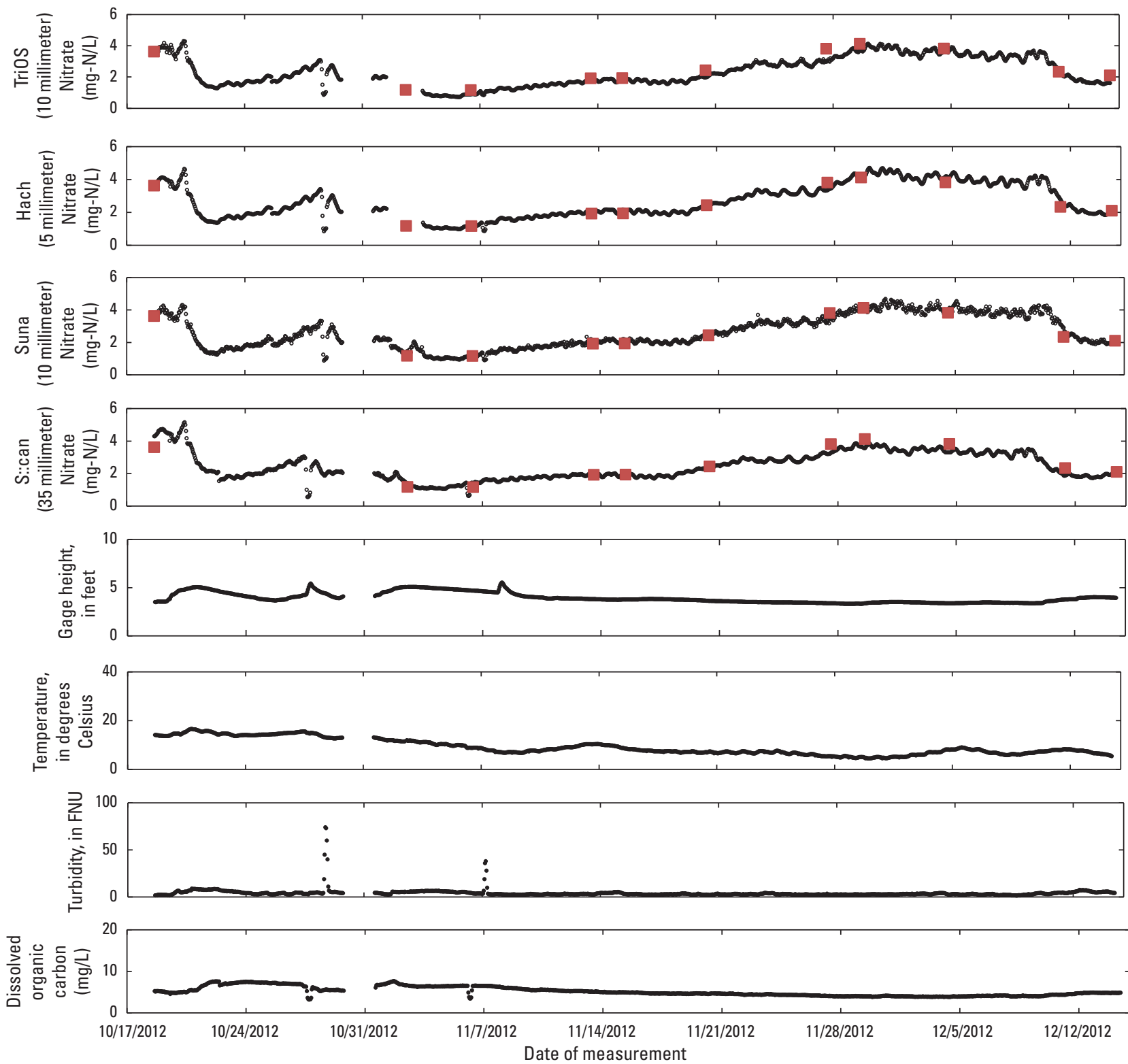

Figure 17. Stacked time series plots for measured nitrate concentration in milligrams nitrogen per liter (mg-N/L) plotted for the Passaic River gage height in feet, temperature in degrees Celsius, turbidity in formazin nephelometric units (FNU), and dissolved organic carbon in milligrams per liter (mg/L). Red boxes represent the reference samples collected from the Passaic River during the testing period. 

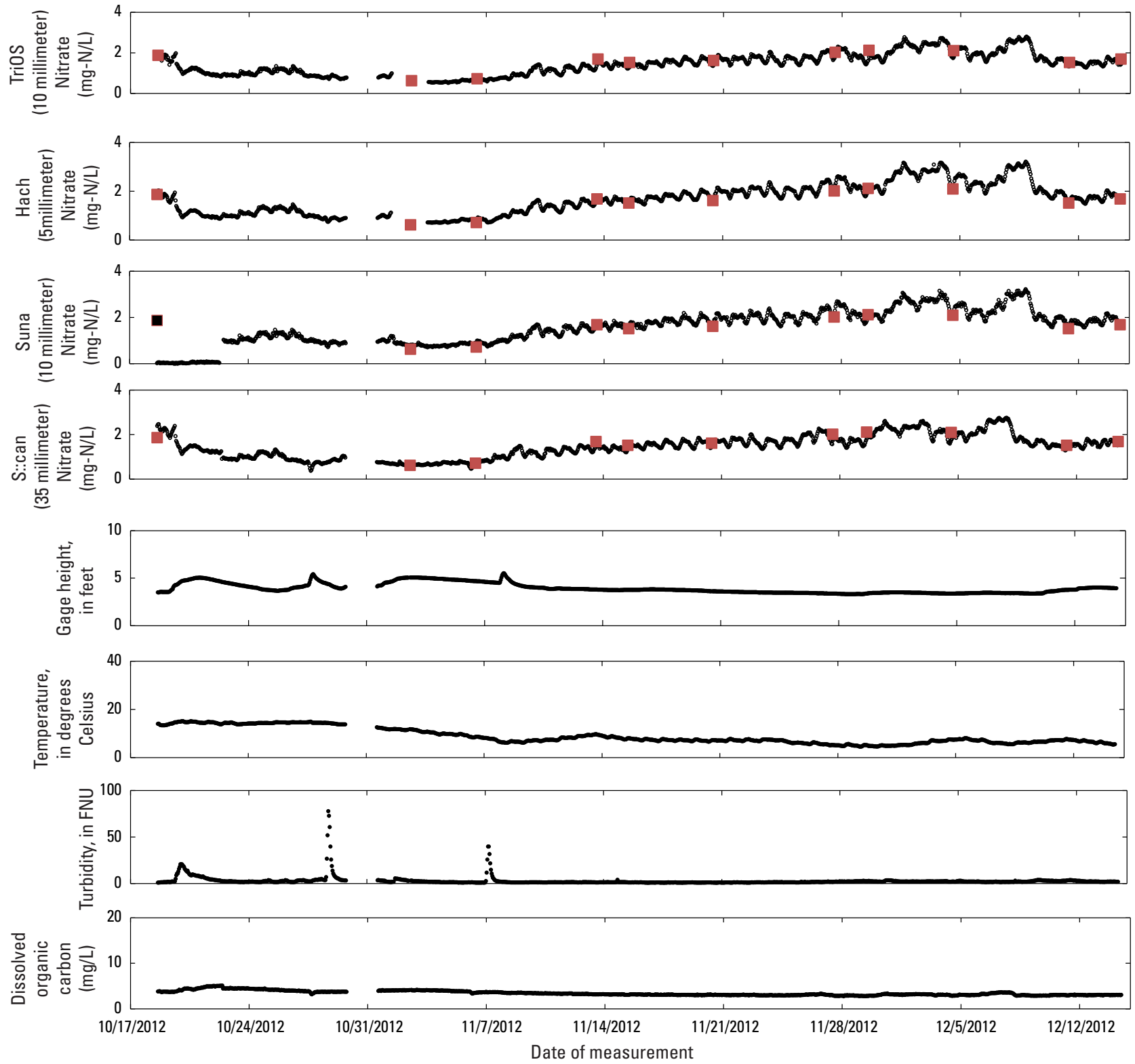

Figure 18. Stacked time series plots for measured nitrate concentration in milligrams nitrogen per liter (mg-N/L) plotted for the Pompton River gage height in feet, temperature in degrees Celsius, turbidity in formazin nephelometric units (FNU), and dissolved organic carbon in milligrams per liter. Red squares represent the reference samples collected from the Pompton River during the testing period. The October 18, 2012, reference point (black square) was not included in the Satlantic Submersible UV Nitrate Analyzer's accuracy evaluation due to the insufficient filling of the sample basin. 

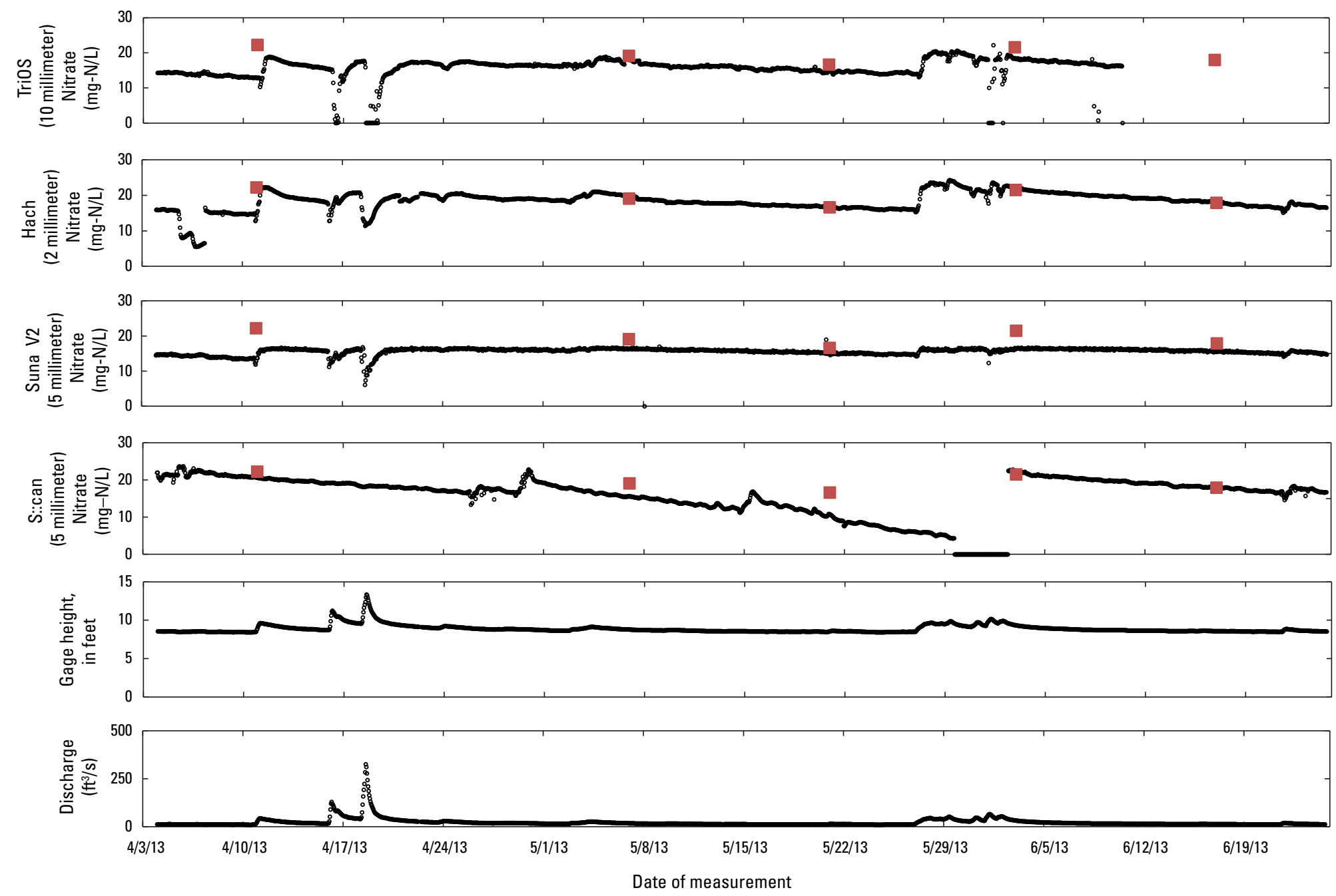

Figure 19. Stacked time series plots for measured nitrate concentration in milligrams nitrogen per liter (mg-N/L) plotted for Kickapoo Creek gage height in feet, and discharge in cubic feet per second $\left(\mathrm{ft}^{3} / \mathrm{s}\right)$. Red squares represent the reference samples collected during the testing period. 

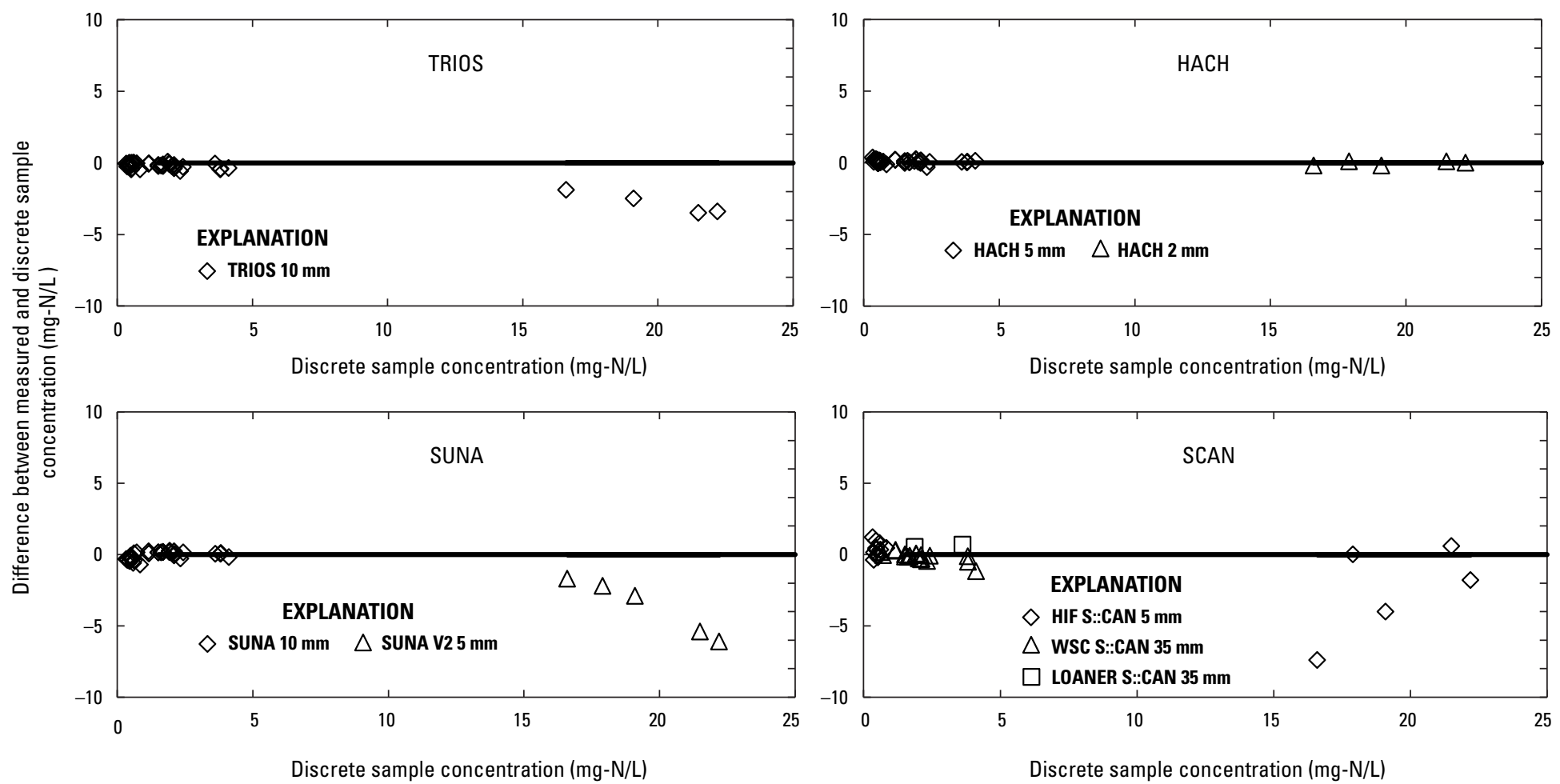

Figure 20. Difference in milligrams nitrogen per liter $(\mathrm{mg}-\mathrm{N} / \mathrm{L})$ between the measured and reference nitrate concentrations from eight analyzers at three USGS sites compared to the reference nitrate concentration. The difference, calculated as measured minus reference concentration, shows any bias in the data. 


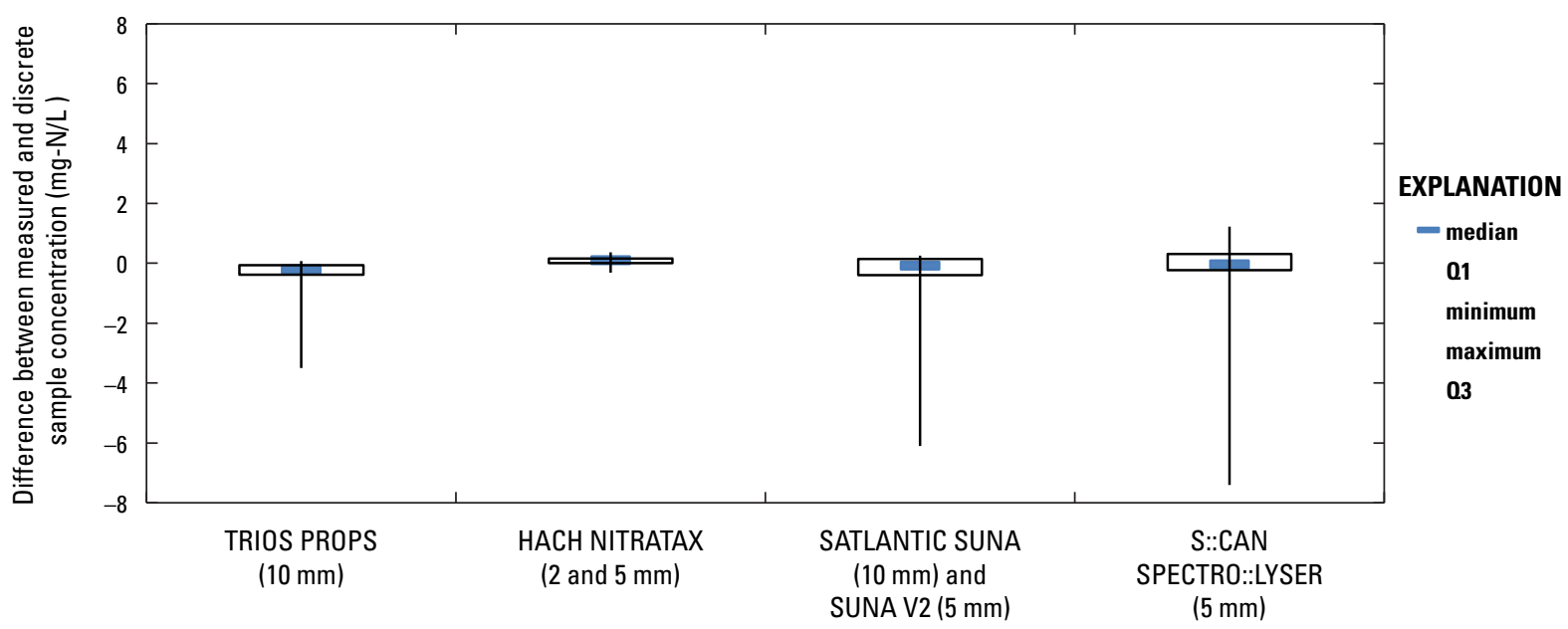

Figure 21. Statistical distribution of the differences in measured and discrete sample nitrate concentration from three measurement sites $(\mathrm{mg}-\mathrm{N} / \mathrm{L}$, milligrams nitrogen per liter; $\mathrm{mm}$, millimeters). 
For additonal information, visit http://water.usgs.gov/hif/ USGS Publishing Service Center staff:

Marilyn A. Billone, Editor

James E. Banton, layout 

